\title{
Métricas para hiperdocumentos Web: uma análise utilizando técnicas de aprendizado de máquina $^{1}$
}

\author{
Elisandra Aparecida Alves da Silva
}

Orientadora: Profa. Dra. Renata Pontin de Mattos Fortes

Dissertação apresentada ao Instituto de Ciências Matemáticas e de Computação - ICMC-USP, como parte dos requisitos para obtenção do titulo de Mestre em Ciências de Computação e Matemática Computacional.

USP - São Carlos

Agosto/2001

\footnotetext{
Trabalho realizado com o apoio financeiro da FAPESP (N.99/020+2-3)
} 


\section{A Comissão Julgadora:}

Profa. Dra. Renata Pontin de Mattos Fortes

Profa. Dra. Maria Carolina Monard

Profa. Dra. Junia Coutinho Anacleto Silva 
A meas pais, por tudo que sempre fizeram por mim.

A meu amor, Marcus, por todo o apoio e compreensão. 


\section{Agradecimentos}

Agradeço primeiramente a Deus, por toda luz, proteção e força, pois sem tudo isso não poderia estar aqui e não conseguiria concluir mais esta etapa de minha vida.

A meus pais, por serem exemplos de amor e luta.

A meu amor, Marcus, obrigada por ser essa pessoa tão especial, carinhosa e amiga. Você sabe o quanto contribuiu para que eu chegasse até aqui.

A minha orientadora, Renata, obrigada pelos conselhos, pelas palavras de incentivo e por todo o apoio que me deu. Tenho certeza de que fez tudo com muito carinho e dedicação. À profa. Maria do Carmo Nicoletti, por ter contribuído com as primeiras idéias para o desenvolvimento deste trabalho.

À Maria Carolina, minha orientadora substituta, obrigada pela força e por tudo que me ensinou.

A meus irmãos, Dréa e Rafa, obrigada por todo amor e por serem essas pessoas tão especiais.

A minhas sobrinhas, Bianca e Luisa, obrigada pelo amor e por toda alegria que me proporcionam. Vocês são muito importantes para a madrinha.

A meus cunhados, Luis e Jaqueline, obrigada pelo carinho.

A meus queridos, Waldir, Terezinha e Gustavo, obrigada por me acolherem com tanto carinho.

A minhas amigas, Paula, Melina, Érika, Michele, Grazielle, Cris, Márcia, Tânia e Lu, obrigada por tudo!

Aos amigos Nelson, Giani, Gleise, Malu e Sheila que, mesmo longe, eu não poderia esquecer. Como foram bons aqueles momentos que passamos juntos, lembram da biblioteca da FOA?

Aos amigos Aline, Dani, Débora e Enzo, obrigada por toda ajuda e amizade.

Aos que me ajudaram na realização do trabalho: Claudinha, Chandler e Kleber.

A todos os colegas do LABES.

A todas as pessoas do ICMC.

À FAPESP, pelo auxilio concedido para realização deste trabalho. 


\section{Resumo}

Com avanço da World Wide Web (WWW) ocorreu um aumento significativo em desenvolvimento de hiperdocumentos Web (websites). Esse desenvolvimento, no entanto, tem se mostrado sujeito a muitos "erros", que em geral são atribuídos à manipulação de um grande número de nós e links. Tentando diminuir esses erros em potencial, muitos trabalhos têm proposto diferentes soluções para auxiliar a avaliação de hiperdocumentos e a aplicação de métricas se apresenta como uma possível abordagem, seguindo os preceitos de Engenharia de Software. Por sua vez, as métricas, em geral, são de difícil interpretação por parte dos webmasters. Assim, neste trabalho investigamos a abordagem de aplicação de métricas a websites contando com auxílio de técnicas de Aprendizado de Máquina (AM). Estas técnicas têm sido utilizadas em uma variedade de tarefas no contexto Web, tais como auxiliar os usuários em suas pesquisas, aprendizado relacionado aos interesses do usuário, extração de informações, entre outras. Este trabalho visa, através do suporte de técnicas de AM, auxiliar a abordagem de análise de métricas de websites. 


\begin{abstract}
With the widespread of the World-Wide-Web there was a significant increase in development of Web hyperdocuments (websites). This development, however, has been shown to be an error-prone activity due to the manipulation of large amount of nodes and links. In order to reduce the errors, several essays have proposed different solutions to help evaluating hyperdocuments and according to Software Engineering theories, metrics usage can be an useful one. But the metrics generally are difficult to be understood by the webmasters. Thus, we propose an approach that considers metrics usage in websites regarding to the support of Machine Learning techniques. The techniques have been used in a variety of Web context tasks, including learning to assist users in searches, learning information extractors, learning user interests, and others. This work focuses on helping the analysis of website metrics using the support of Machine Learning techniques.
\end{abstract}




\section{Índice}

CAPÍTULO 1 - INTRODUÇÃO

1.1. CONTEXTO 1

1.2. OBJETIVOS 2

1.3. ORGANIZAÇ:ẮO

CAPÍTULO 2 - QUALIDADE DE SOFTWARE, DE HIPERMÍDIA E DE APLICAÇÕES WEB 4

2.1. CONSIDERAÇÕES INICIAIS

2.2. Qualidade DE Software 4

2.3. QUALIDADE HIPERMIDIA 7

2.4. QUALLIDADE DE APLICAÇOELS WLB

2.5. CONSIDERAÇÕES Finais

CAPÍTULO 3 - AS MÉTRICAS DE HIPERDOCUMENTOS ESTUDADAS

3.1. CONSIDERAÇÕES INICIAIS

3.2. AS MÉTRICAS DE HIPERDOCUMENTOS ESTUDADAS

3.3. CONSIDIRAÇOIES FINAIS

CAPÍTULO 4 - A ABORDAGEM UTILIZADA PARA ANÁLISE DAS MÉTRICAS UTILIZANDO TÉCNICAS DE APRENDIZADO DE MÁQUINA

4.1. CONSIDERAÇÕES INICIAIS

4.2. FERRAMENTA DB-LiOS 29

4.2.1. Considerações sobre os dados coletados pela ferramenta DB-LiOS 32

4.3. As MÉTRICAS ESCOLHIDAS

4.3.1. Métricas aplicadas a sites $\quad 36$

4.3.2. Métricas aplicadas a páginas 38

4.4. Aprenizizado de máquina para auxiliak a análise das MÉtricas

4.4.1. Metodologia utilizada 40

4.4.2. Clusters versus Classes

4.4.3. Processo utilizado para Explicação dos Clusters

4.5. CONSIDERAÇÕ ES FinAIS $\quad 45$

CAPÍTULO 5 - O EXPERIMENTO REALIZADO UTILIZANDO A ABORDAGEM PROPOSTA 47

5.1. CONSIDIRACOOHS INICINIS

5.2. AS ETAPAS DO EXPERIMENTO

5.2.1. Utilizaçāo da ferramenta DB-LiOS 48

5.2.2. Aplicação dos módulos responsáveis pela obtenção dos valores das métricas de sites e páginas 48

5.2.3. Utilização do Autoclass $\quad 50$ 
5.2.4. Utilização do Inclass 51

5.2.5. Utilização do See 5 51

5.2.6. Análise dos resultados 51

5.3. CARACTERISTICAS DA INFRA-ESTRUTUURA DE REAL.IZAC C̄O DO EXPERIMENTO) 53

5.4. Considerações Finais 54

CAPÍTULO 6 - CONCLUSÕES 55

6.1. CONCLUSÕEs E CONTRIBUtÇóES 55

6.2. TRABalhos Futuros 56

BIBLIOGRAFIA

58 


\section{Índice de Figuras}

Figitra 1. Eitás do Ciclo de Vida por Prototipação Evolutiva [Fortes, 1996]

Figitira 2. Processo para desenvolvimento de aplicaçŏes Web [Pressman, 2000]

Figura 3. ÁRVORE de REQUisitos de QUALIDAde PARA APLiCAÇÕEs WEB [PRESSMAN, 2000]

FIGURA 4. UM GRAFO REPRESENTANDO UM HIPERDOCUMENTO

FigURA 5. MATRIZ distâNCIA E MATRIZ DISTÂNCIA CONVERTIDA

Figura 6. UM HIPERDOCUMENTO WEB E SUA MATRIZ DE ADJACENCIA

Figura 7. Algokitmo para obtenÇão da matriz de mínimo Caminho 37

Figura 8. Algoritmo de Robert-Ferland [SZWarcfiter, 1984] 37

Figura 9. UM dígRAFo E SUA MATRIZ DE MíNIMO CAMINHO 37

Figura 10. Metodologia UtIlizada [Martins \& MONard, 2000] 41

FIGURA 11. CONJUNTO DE EXEMPLOS DE TREINAMENTO [MARTINS ET AL., 2001] 41

FiguRA 12. CONIUNTO DE EXEMPLOS DE TREINAMENTO VISTO PELO ALGORITMO DE CLUSTERING [MARTINS ET AL., 2001]

FIGURA 13. CONUINTO DIE EXEMPPIOS DI: TREINAMENTO AGRUPADOSS EM CLUISTERS IMARIINS IET AL.., 2OOII 42

Figura 14. Processo utilizado para explicação dos clusters

FigURA 15. REgRAS EXTRAIDAS PARA TODOS OS SITES 


\section{Índice de Tabelas}

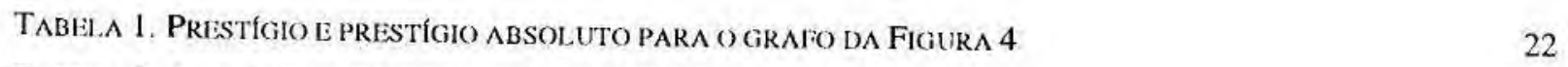

TABELA 2. A INFORMAÇÃO FORNECIDA POR DB-LiOS

TABELA 3. OS SITES UTILIZADOS NO EXPERIMENTO

TABEI.A 4. AIGUIMAS PÁGINAS E VAIORES PARA AS MÉTRICAS IDE PÁGINAS DO SITE NÚMERO) 1

TABIILA 5. OS VALORLSS OBTHDOS P'ARA AS METRICAS DE STTES

TABELA 6. UM DOS RESULTADOS DO AUTOCLASS

TABEL.A 7. RESULTADO DO INCLASS

TABLLA 8. EXPERIMENTO COM TODOS OS STTES - RESUMO DOS RESULTADOS 


\section{Capítulo 1 - Introdução}

\subsection{Contexto}

O avanço da $W W W^{1}$ propiciou um aumento significativo em desenvolvimento de hiperdocumentos (websites) ${ }^{2}$. Devido à natureza dinâmica das alterações das informações e da quantidade de informação a ser processada, o projeto e a manutenção dos hiperdocumentos se apresentam como atividades bastante custosas que, se não abordadas sistemática e cuidadosamente, podem causar problemas em relação à qualidade do serviço de disponibilização de informações.

O projeto de websites não é um processo totalmente bem definido [Fortes \& Nicoletti, 1997a], e são muitos os aspectos, relacionados à produção de um "bom" hiperdocumento, que devem ser considerados. Entre eles, especial atenção deve ser dada à diversidade de usuários e de domínios de informação. Visto que o projeto de websites possibilita maneiras alternativas de se organizar informações e que essas alternativas devem atender a uma variedade de requisitos de seus diversos usuários, não existem regras definitivas a serem seguidas que garantam um projeto do melhor hiperdocumento. A inexistência de alguma regra que pudesse ser considerada para se avaliar o hiperdocumento, durante seu processo de desenvolvimento, traz dificuldades à tarefa de autoria; tais dificuldades perduram e muitas vezes se agravam durante a manutenção. Por sua vez, essas dificuldades se mostram como possíveis razões para a existência de tantos hiperdocumentos de pouca qualidade, especialmente considerando-se sua organização estrutural.

Algumas propriedades de hiperdocumentos, identificadas em [Thistlewaite, 1995], que podem ser verificadas para identificar estruturas de hiperdocumentos mal projetadas são: falta de consistência na criação de links, que ocorre quando mais de uma pessoa cria links manualmente [Ellis et al., 1994]; falta de links entre conteúdos de informação que o usuário espera que estejam relacionados; existência de links entre conteúdos de informação que o usuário não espera que estejam relacionados; e dificuldade de manutenção.

\footnotetext{
${ }_{2}^{1}$ WWW (World Wide Web) será doravante referenciada por Web nesta dissertação.

${ }^{2}$ Neste trabalho, hiperdocumentos Web, aplicações hipermídia desenvolvidas na Web, websites e sites são termos utilizados indistintament $\theta$.
} 
Devido à flexibilidade na criação/atualização de links em hiperdocumentos da Web e aos problemas associados com suas estruturas mal projetadas, neste trabalho investigamos propriedades de links que possam ser classificadas. Assim, como resultado dessa classificação, um feedback é fornecido para análise pelos webmasters, durante a autoria e manutenção de hiperdocumentos.

O feedback desenvolvido neste trabalho se refere ao resultado da aplicaçäo de métricas de hiperdocumentos, propostas na literatura, e outras por nós sugeridas, a websites. Segundo [Mendes et al., 2001], métricas podem ser usadas para avaliar a qualidade e o desenvolvimento de websites, assim como para obter feedback de maneira a auxiliar o entendimento, controle, melhorias, e prognósticos sobre tais produtos e processos.

Nesse sentido, este trabalho propõe uma abordagem para auxiliar a análise dos valores obtidos a partir de métricas de websites. As métricas utilizadas nessa abordagem se referem a um subconjunto de métricas propostas na literatura para analisar hiperdocumentos. Em especial, por serem métricas de difícil interpretação por parte dos webmasters e por terem sido definidas para hiperdocumentos em geral (não exclusivamente para websites), a abordagem conta com auxílio de técnicas de Aprendizado de Máquina.

Aprendizado de Máquina (AM) é uma subárea de Inteligência Artificial (IA) que pesquisa métodos computacionais relacionados à aquisição de novos conhecimentos, novas habilidades e novas formas de organizar o conhecimento já existente. Essa subárea de IA tem sido muito explorada no contexto Web [Craven \& Slattery, 2001], [Craven et al., 2000], [Pazzani \& Billsus, 1997], visto que a Web fornece um domínio muito interessante para uma variedade de tarefas de AM, incluindo auxiliar os usuários em suas pesquisas, aprendizado relacionado aos interesses do usuário, extratores de informação, e outros.

\subsection{Objetivos}

Diversas métricas para avaliação de hiperdocumentos têm sido propostas, mas pouca avaliação experimental e acompanhamento de seus valores foram realizados até o momento. Análises realizadas nesse sentido podem contribuir para uma melhoria ou adequação na definição dessas métricas.

O objetivo deste trabalho é apresentar uma abordagem para auxiliar a análise de métricas de hiperdocumentos Web, propostas na literatura e outras por nós sugeridas. Devido aos valores das métricas, na maioria das vezes, não serem de fácil interpretação, a abordagem utiliza técnicas de Aprendizado de Máquina para proporcionar melhor entendimento por parte dos webmasters. Com o diferencial de incorporar o suporte de AM de Inteligência 
Artificial, a abordagem proposta, inicialmente caracterizada das áreas de Engenharia de Software e de Hipermídia, se configura interdisciplinar, do ponto de vista das Ciências da Computação. Adicionalmente, por meio de um experimento com dados reais de websites de universidades brasileiras, a abordagem é ilustrada.

\subsection{Organização}

Este trabalho está dividido em seis capítulos. Neste capitulo de Introdução foi descrito o trabalho de forma geral, com seus objetivos e motivações.

No Capítulo 2, uma visão geral de qualidade de software, qualidade hipermídia e, qualidade de aplicações Web são apresentadas.

No Capítulo 3 as métricas estudadas neste trabalho são descritas.

No Capítulo 4 a abordagem proposta para análise dos valores obtidos para as métricas é apresentada.

No Capítulo 5 o experimento realizado, aplicando a abordagem descrita no Capítulo 4, é relatado. E finalmente, no Capítulo 6 são apresentadas as conclusões. 


\section{Capítulo 2 - Qualidade de software, de hipermídia e de aplicações Web}

\subsection{Considerações Iniciais}

$\mathrm{Na}$ década de 90 começaram a surgir trabalhos voltados para avaliação de hiperdocumentos. Nesta época, [Brown, 1990] destacou que o auxílio de ferramentas automáticas para avaliação de características inerentes ao hiperdocumento seria um suporte fundamental para a atividade humana de análise da qualidade de hiperdocumentos. Entretanto, Brown não indicou como e quais características deveriam ser obtidas.

Os paradigmas úteis e mais adequados para a tarefa de análise e avaliação da qualidade de hiperdocumentos poderiam então surgir a partir da experiência prática nas áreas de Engenharia de Software e de Métricas de Software, segundo [Hatzimanikatis et al., 1995].

Em trabalho mais recente, [Mendes et al., 2001] propõem que métricas sejam usadas para avaliar a qualidade e o desenvolvimento de aplicações Web, assim como para obter feedback de maneira a auxiliar o entendimento, controle, melhorias, e prognósticos sobre tais produtos e processos.

Por ser o tema mais amplo sobre o qual este trabalho foi realizado, este capítulo apresenta na Seção 2.2 uma visão geral de qualidade de software. Na Seção 2.3, o enfoque é na qualidade hipermídia e, na Seção 2.4, qualidade de aplicações Web.

\subsection{Qualidade de Software}

A Engenharia de Software é uma disciplina que aplica os princípios de engenharia com o objetivo de produzir software de alta qualidade a baixo custo. A qualidade do produto de software deve ser um objetivo constante do processo de desenvolvimento [Sanches et al., 2000].

Durante todo o processo de software, existem atividades que devem ser realizadas para assegurar que a qualidade seja mantida, bem como para que o produto final de software 
tenha qualidade. A aplicação de métricas é uma dessas atividades e refere-se a: (a) obtenção de um conjunto de medidas do software para indicar a qualidade do produto, (b) avaliação da produtividade das pessoas que produzem o produto, (c) avaliação dos benefícios (em termos de produtividade e qualidade) derivados de novos métodos e ferramentas de engenharia de software, (d) formação de uma base para as estimativas e assim auxiliar na justificativa de pedidos de novas ferramentas ou treinamento adicional. No entanto, caracterizar um produto de software que possua qualidade depende ainda do ponto de vista que é considerado: do usuário, do desenvolvedor e do gerente.

Na visão do usuário o interesse fica concentrado principalmente no uso do software; na visão do desenvolvedor, a qualidade fica mais voltada às características internas do software; e na visão do gerente, a qualidade do produto não pode ser desvinculada dos interesses da organização.

Além disso, um outro fator que interfere na qualidade do produto de software é o tipo da aplicação, ou seja, o seu domínio de informação. É natural que para sistemas de tipos diferentes, como software básico, sistemas comercias, sistemas de tempo-real, etc., a qualidade do produto seja avaliada por um conjunto de características com prioridades diferentes de um tipo de software para outro [Sanches et al., 2000].

Portanto, ao ser considerada a variedade possivel de valores para esses fatores (pontos de vista e tipo da aplicação), pode-se perceber que alguns deles estão mais associados ao produto propriamente dito e outros ao processo de desenvolvimento. Convém ressaltar que mesmo aqueles naturalmente associados ao produto dependem fundamental e indiretamente do processo. Mas, de maneira geral, os estudos na área de qualidade de software têm sido realizados seguindo duas abordagens: qualidade do produto software e qualidade do processo de software.

Como qualidade do processo de software é difícil de ser colocada em prática, modelos de melhoria de processo propõem que estratégias sirvam como guia de orientação. Essas estratégias permitem que se compreenda o estado atual do processo, se desenvolva a visão do processo desejado, se estabeleça uma lista de ações necessárias à melhoria do processo, em ordem de prioridade, e que se gere um plano para acompanhar as ações e alocação de recursos para execução do plano [Sanches et al., 2000]. Vale observar que para se compreender o estado atual do processo, o mecanismo adotado é o de obtenção de medidas dos artefatos que são produzidos durante o mesmo. 
Para se julgar a qualidade do produto software, segundo [Sanches et al., 2000], o estado da arte em tecnologia de software ainda não apresenta um esquema de descrição de seus atributos de qualidade bem definido e amplamente aceito. Mesmo proposições bem sucedidas, trazem dificuldades de aplicação devido aos muitos aspectos de qualidade. Como conseqüência, o comitê técnico da ISO/IEC continua realizando esforços no sentido de se desenvolver um consenso e encorajar a padronização em nível mundial de um modelo padronizado para qualidade do produto.

As primeiras tentativas de padronização surgiram em 1978 e em 1985 foi iniciado o desenvolvimento da Norma Internacional ISO/IEC 9126 - "Information Technology - Software product evaluation - Quality characteristics and guidelines for their use", publicada em sua primeira versão em 1991 [ISO/IEC 9126]. A Norma NBR 13596 é uma tradução da norma ISO-IEC 9126, feita pela comissão de Estudos de Qualidade de Software do Subcomitê de Software do Comitê de Informática da ABNT (Associação Brasileira de Normas Técnicas), publicada em agosto de 1996. Na NBR 13596 são listados os seis fatores que devem ser verificados em um software para que ele seja considerado um "software de qualidade". Esses fatores são:

- Funcionalidade: Conjunto de atributos que indicam a existência de um conjunto de funções e suas propriedades especificadas. As funções são as que satisfazem as necessidades explícitas ou implícitas.

- Confiabilidade: Conjunto de atributos que indicam a capacidade do software de manter seu nível de desempenho sob condições estabelecidas durante um período de tempo estabelecido.

- Usabilidade: Conjunto de atributos que indicam o esforço necessário para se poder utilizar o software, bem como o julgamento individual desse uso, por um conjunto de usuários. A usabilidade deve levar em conta os vários ambientes dos usuários que o software pode afetar, que pode abranger desde a preparação para uso até a avaliação dos resultados. A usabilidade, definida na Norma como um conjunto específico de atributos de um produto de software, é diferente do ponto de vista ergonômico, em que outras características como eficiência e eficácia também são considerados componentes de usabilidade.

- Eficiência: Conjunto de atributos que indicam o relacionamento entre o nível de desempenho do software e a quantidade de recursos usados, sob condições estabelecidas. Os recursos podem incluir outros produtos de software, hardware, materiais (por exemplo: papel para a impressora, discos flexíveis) e serviços de operação, manutenção ou suporte. 
- Manutenibilidade: Conjunto de atributos que indicam o esforço necessário para fazer modificações especificadas no software devido a mudanças de ambiente, ou nos seus requisitos.

- Portabilidade: Conjunto de atributos que indicam a capacidade do software de ser transferido de um ambiente para outro. $\mathrm{O}$ ambiente pode incluir ambiente organizacional, de hardware ou de software.

Considerando-se que hipermidia enquadra-se como um tipo especial de software, esse conjunto de fatores de qualidade também deve ser considerado em sua avaliação de qualidade. No entanto, em função de características inerentes aos principais problemas relacionados ao produto hipermídia, os estudos aqui descritos foram orientados pela busca dos principais fatores de qualidade a serem prioritariamente observados.

Na próxima seção são apresentados os estudos realizados na área de qualidade hipermídia, considerando-se tanto avaliação do produto quanto avaliação do processo de desenvolvimento hipermídia.

\subsection{Qualidade hipermídia}

Hiperdocumento, ou aplicação hipermídia, trata-se de um produto de software com características bem estabelecidas: consiste basicamente de um conjunto de fragmentos de informação interligados, cada nó (node) é uma unidade de informação e a interligação (link) conecta esses nós de maneira arbitrária. A estrutura do hiperdocumento é a rede de nós e links. Quando essa rede é composta por muitos nós e links, os problemas típicos, constatados na literatura, que podem surgir durante a navegação são:

- sobrecarga cognitiva: que corresponde ao esforço e concentração exigidos do usuário devido à necessidade de se manter várias tarefas ou caminhos ao mesmo tempo [Conklin, 1987];

- desorientação do usuário: que ocorre devido à tendência do usuário de se perder na navegação pelo hiperdocumento [Halasz, 1988];

- falta de coerência: que se manifesta devido à dificuldade de identificação dos principais componentes do hiperdocumento; isso ocorre quando os autores não utilizam recursos para ajudar os usuários a identificarem esses componentes e a maneira com a qual eles constituem sua estrutura global [Thüring et al., 1995].

Em função desses problemas típicos relacionados ao produto hipermídia, diversas pesquisas têm sido realizadas com o objetivo de apresentar alternativas para minimizá-los. 
Em especial, várias propostas de suporte à avaliação de hiperdocumentos mostram como os fatores de qualidade podem ser observados.

[Stotts et al., 1992] propuseram um método para avaliação de hiperdocumentos, avaliação esta baseada somente no comportamento dos links. Os autores enfatizam que a navegação, cujo componente básico é o link, é adequada quando são considerados a capacidade, características e os auxilios de navegação suportados pelo browser (navegador). Por exemplo: se um leitor navega para um nó que não possui nenhum link de saída, o único recurso disponivel para continuar sua navegação é voltar à página anterior ou inicial através dos recursos do browser. O método proposto reduz a ênfase no browser e concentra-se na estrutura do hiperdocumento, e assim, contribui para uma verificação da qualidade contida na estrutura do hiperdocumento. O objetivo do método é analisar propriedades semânticas de um hiperdocumento verificando somente os links.

Para [Hatzimanikatis et al., 1995], os princípios para análise e avaliação da qualidade de hiperdocumentos podem ser adotados de forma similar aos da Engenharia de Software, a partir de Métricas de Software. Definem, dessa forma, um modelo de qualidade de hiperdocumento baseado nas idéias do modelo hierárquico Fator-Critério-Métrica ${ }^{3}$ (FCM), utilizado na área de Qualidade de Software.

A abordagem do modelo FCM consiste em identificar atributos-chave da qualidade de um produto de software, denominados fatores de qualidade. Os fatores são abstratos por natureza, assim como a própria qualidade, e devem ser posteriormente decompostos em atributos de nivel mais detalhado, denominados critérios de qualidade. Cada fator pode ter qualquer número de critérios e cada critério pode afetar qualquer número de fatores.

Uma vez que os critérios de qualidade não são diretamente mensuráveis, um nível a mais de decomposição é necessário para a definição de métricas para cada critério. À medida que essa decomposição de fatores em critérios e desses em métricas procede, obtém-se variáveis mensuráveis em um determinado domínio. Observa-se que o FCM pode ser adaptado para ambientes diversos, pois diferentes fatores, critérios e métricas podem ser definidos, conforme o objetivo de qualidade estabelecido.

Os fatores de qualidade legibilidade e manutenibilidade de um hiperdocumento, bem como os critérios correspondentes, são considerados como prioritários por Hatzimanikatis et al.. Além deles, são apresentadas as métricas de estrutura que podem ser coletadas para subsidiar a avaliação desses critérios, as quais são computadas a partir do grafo que

\footnotetext{
${ }^{3}$ Modelo de qualidade Factor-Criteria-Metric (FCM) de McCall 1977.
} 
representa a estrutura do hiperdocumento. A maioria dessas métricas é derivada das métricas aplicadas a softwares.

O fator de qualidade legibilidade é um conceito que deve indicar a facilidade de se "ler" um hiperdocumento. Esse fator de qualidade representa o esforço requerido do usuário para "ler" o hiperdocumento, ou seja, para navegar sobre ele e entender a estrutura das idéias nele contidas. Algumas das questões importantes relacionadas a esse fator são:

- 'O leitor pode facilmente ficar "perdido no hiperespaço"?'

- 'Existem mapas ou outras facilidades disponiveis?'

- 'O hiperdocumento está consistente?', ou seja, as idéias contidas nos nós estão organizadas de forma coerente de modo a não possibilitar divergências.

- 'Os conteúdos dos nós estão corretos e são facilmente compreensíveis?'

Manutenibilidade é o conceito associado à medida da dificuldade requerida para estender, modificar ou corrigir o hiperdocumento, num momento posterior à sua criação. Representa o esforço requerido de um autor para manter um hiperdocumento, que pode ter sido criado por outra pessoa. Questões importantes relativas à manutenibilidade são:

- 'Existe documentação de projeto disponivel?'

- 'Existe, incluído no hiperdocumento, algum comentário do autor sobre a estrutura dos documentos?'

- 'É fácil entender as intenções e o "estilo de autoria" do autor original?'

Hatzimanikatis et al. destacam também que há uma estreita relação entre navegação e manutenção. Quanto mais dificeis forem a navegação e a compreensão de um hiperdocumento, mais difícil será sua manutenção. Além disso, quando alguém deseja mudar ou estender um hiperdocumento, deve também ter conhecimento da maneira pela qual o autor original utilizou os efeitos de apresentação e de estrutura, bem como um bom entendimento da organização geral do hiperdocumento.

No trabalho de [Nanard \& Nanard, 1995] a preocupação é com a qualidade do projeto do hiperdocumento. Dessa forma, a proposta se enquadra como uma contribuição para a qualidade do processo de desenvolvimento de hipermídia. Eles consideram que o desenvolvimento real de um hiperdocumento não segue apenas os passos de um método convencional de projeto, mas também um projeto mental. As etapas de um método convencional: modelagem de domínio, modelagem de navegação, projeto de interface, implementação e realização de testes. As etapas do projeto mental são: geração de material, organização e estruturação, reorganização e alteração e, avaliação. 
Outro método para avaliação de qualidade do processo foi proposto por [Garzotto et al., 1995]. Conhecido como método de avaliação "Orientado a Projetos", Garzotto et al. mostraram sua utilização em uma aplicação comercial (o software "Art Galery" da Microsoft). As cinco dimensões consideradas pelos autores para analisar uma aplicação hipermídia são: conteúdo, estrutura, apresentação, dinâmica e interação, conforme descritas a seguir:

- Conteúdo: refere-se ao tipo de informação que é incluída na aplicação. Esses tipos podem ser: mídia estática (como dados formatados - por exemplo: data, cadeias de caracteres, imagens e gráficos) ou mídia ativa (como vídeos, trilhas sonoras e animações). O conteúdo pode ser a dimensão mais importante na avaliação de uma aplicação hipermídia, mas para que seja feita, é necessário um especialista do domínio da aplicação, assim como um conhecimento profundo do perfil dos usuários finais e de suas atividades.

- Estrutura: refere-se à organização do conteúdo.

- Apresentação: refere-se a como o conteúdo e as funções da aplicação são mostrados aos usuários. Para apresentação da mídia estática somente uma exibição das informações ("display") é necessária, mas no caso da mídia ativa é exigida uma elaboração melhor para que possa ser exibida ("playing").

- Dinâmica: refere-se a como os usuários interagem com as informações e interagem através delas (por exemplo, o controle de uma mídia ativa).

- Interação: refere-se a verificação da funcionalidade da dinâmica da aplicação pela operação dos elementos da apresentação. Levando em consideração que a interação combina os fatores de dinâmica e apresentação, muitos autores consideram a interação como parte da dinâmica ou apresentação.

Esse método de avaliação "Orientado a Projeto" considera além das dimensões descritas, um subconjunto de critérios de avaliação, composto pelos seguintes atributos de qualidade:

- Riqueza: expressa a abundância de itens de informação e os caminhos disponiveis para se obtê-los.

- Facilidade: mede o grau de facilidade dos usuários acessarem as informações e o grau de entendimento das operações necessárias para conseguir este acesso.

- Consistência: regularidade da aplicação, em outras palavras significa avaliar a forma de tratamento de elementos com conceitos similares ou distintos.

- Auto-evidência: expressa a facilidade do usuário adivinhar o significado e o propósito das informações que são exibidas. Essas informações podem se referir ao conteúdo ou aos elementos de navegação. 
- Previsibilidade: expressa a facilidade do usuário de prever o resultado de uma operação.

- Legibilidade: expressa todas as opiniões sobre a validade da aplicação e os autores também consideram que a legibilidade depende de todos os atributos descritos (riqueza, facilidade, consistência, auto-evidência e previsibilidade). O atributo legibilidade foi considerado como fator de qualidade por [Hatzimanikatis et al., 1995].

- Reuso: visa à reutilização de objetos e operações em diferentes contextos e para diferentes propósitos. Algumas razões pelas quais o reuso deve ser utilizado são: promover consistência e previsibilidade, diminuindo a sobrecarga cognitiva e apresentar o material sob diferentes perspectivas e pontos de vista, enriquecendo a aplicação. Além disso, o reuso possui outras vantagens originadas da Engenharia de Software, por exemplo: reduzir erros, esforços de desenvolvimento e minimizar espaço físico.

Mais recentemente, [Garzotto \& Paolini, 1999] discutem os problemas de usabilidade nas aplicações hipermídia, bem como os esforços feitos no projeto da aplicação. Uma metodologia de avaliação foi então proposta e conta com duas idéias básicas que são: 1) Inspeção - avaliação da aplicação hipermídia por um expert, sem a interferência de usuários, 2) Executar essa inspeção eficientemente. Essas inspeções são feitas através de patterns de inspeção, que conta com diretrizes a serem consideradas pelo inspetor, quando diante de inconsistências e problemas de usabilidade.

[Fortes, 1996] propôs um modelo de ciclo de vida de prototipação evolutiva para hiperdocumento, apresentado na Figura 1. Esse ciclo de vida consiste de quatro etapas: Análise de Requisitos, Autoria, Exame para Avaliação e Reorganização. A ênfase no andamento das etapas é dada à abordagem evolutiva do produto hipermídia em desenvolvimento contínuo. Assim, após cada exame de avaliação, o hiperdocumento é melhorado (por meio de reorganização e autoria) e novas iteraçōes prosseguem até a obtenção de um produto que tenha qualidade.

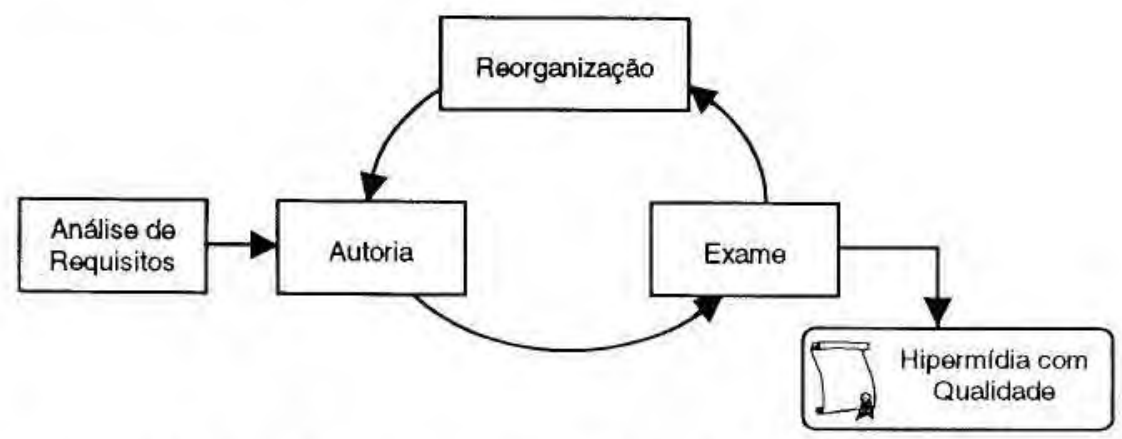

Figura 1. Etapas do Ciclo de Vida por Prototipação Evolutiva [Fortes, 1996]. 
A etapa de Análise de Requisitos engloba atividades como: identificação das necessidades de desenvolvimento da aplicação; identificação dos objetivos do hiperdocumento; análise de mercado e do usuário; levantamento das restrições gerais de software e de hardware; identificação do domínio de informações e de suas fontes; obtenção de permissão de uso de informações; levantamento e análise dos requisitos de navegação e análise de custo e benefício. É nesta fase que o modelo conceitual é elaborado, com as informações que estarão disponiveis no hiperdocumento.

Uma vez que o modelo conceitual esteja definido, passa-se para a etapa de autoria que consiste das seguintes tarefas: organização das informações (elaboração de um projeto) e criação de uma primeira versão do hiperdocumento com base no projeto criado. A reorganização por sua vez, consiste em reformular o hiperdocumento, atendendo os problemas encontrados na etapa de exame. Uma vez reorganizado o hiperdocumento, o mesmo entra no ciclo de melhoria contínua até obter o nível de qualidade desejado. A diferença entre a reorganização e a análise de requisitos, é que na análise não existe nenhum produto, enquanto que na reorganização o produto já se encontra criado e já passou por etapas de exame.

A etapa de exame é que dá suporte à avaliação de qualidade do hiperdocumento. Como já foi mencionado, para que haja uma avaliação da qualidade, devem ser identificados atributos observáveis para atender a todos os pontos de vista dos usuários do hiperdocumento, ou seja, os requisitos esperados por usuários e desenvolvedores. Vale ressaltar também que esses requisitos devem ser condizentes com o domínio da aplicação em questão.

Com base nesse ciclo de vida de prototipação evolutiva e sabendo da necessidade de um suporte para a avaliação que pudesse ajudar aos autores de hipermídia, [Fortes, 1996] propôs então uma avaliação com base na estrutura do hiperdocumento. Posteriormente, métricas relativas ao reuso de links foram definidas [Fortes \& Nicoletti, 1999], [Fortes \& Nicoletti, 1997a]. Para coleta de valores para essas métricas, foi desenvolvida a ferramenta LiOS [Fortes \& Nicoletti, 1997b], que parcialmente serviu de base para os módulos computacionais que foram desenvolvidos neste trabalho.

Todos os trabalhos estudados foram propostos visando avaliação de hiperdocumentos durante o processo de desenvolvimento, levando-se em conta o produto sendo construído. Na próxima seção, por ser o alvo específico deste trabalho, são descritos os fundamentos da literatura sobre o tópico de qualidade de aplicações Web. 


\subsection{Qualidade de aplicações Web}

O modelo de ciclo de vida proposto por [Fortes, 1996] para desenvolvimento hipermídia concentra-se especialmente nas atividades técnicas do processo. Mais recentemente [Pressman, 2000] apresentou um processo para desenvolvimento de aplicações Web, ilustrado na Figura 2, que inclui as atividades que complementam aquelas relacionadas exclusivamente a técnicas de produção de software. O processo engloba as seguintes atividades: Formulação, Planejamento, Análise, Engenharia, Geração de página e Teste, e Avaliação do Usuário.

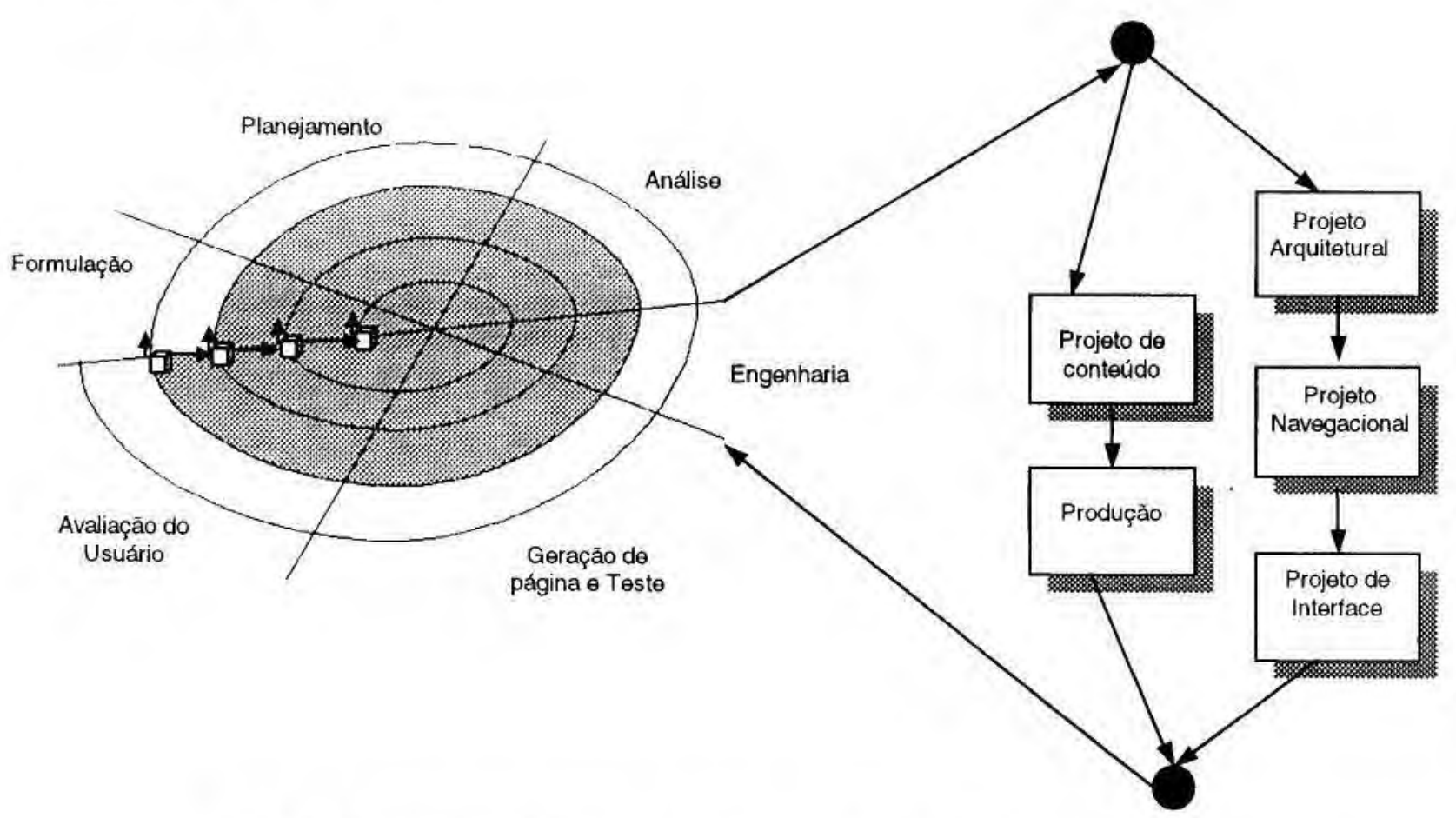

Figura 2. Processo para desenvolvimento de aplicações Web [Pressman, 2000].

A atividade de Formulação permite que usuários e desenvolvedores estabeleçam um conjunto de objetivos comuns para a construção da aplicação e também identifica o escopo do esforço de desenvolvimento. A atividade de Planejamento estima custos de projeto, avalia os riscos associados ao esforço de desenvolvimento e define um cronograma de desenvolvimento.

A atividade de Análise estabelece os requisitos técnicos da aplicação e identifica os itens de conteúdo que serão incorporados à mesma. O escopo definido durante a Formulação é elaborado criando assim um modelo de análise completo da aplicação. Quatro diferentes tipos de análise são conduzidos durante essa atividade:

- Análise de conteúdo: o conteúdo completo da aplicação é identificado. O conteúdo inclui textos, gráficos e imagens, vídeos e áudio. 
- Análise de Interação: o modo no qual o usuário pode interagir com a aplicação é descrito detalhadamente.

- Análise Funcional: os cenários de uso criados como parte da Análise de Interação que definem as operações aplicadas ao conteúdo e outras funções de processamento são utilizados e todas as operações e funções são descritas nesta atividade.

- Análise de Configuração: o ambiente e infra-estrutura da aplicação são descritos em detalhes.

A atividade de Engenharia incorpora duas tarefas paralelas: Projeto de conteúdo e Produção. O objetivo dessas tarefas é projetar, produzir e adquirir todo o conteúdo de texto, gráfico, áudio e vídeo que serão integrados à aplicação. Ao mesmo tempo, o seguinte conjunto de atividades técnicas é conduzido:

- Projeto Arquitetural: Definição da estrutura da aplicação

- Projeto Navegacional: Definição dos caminhos que possibilitam ao usuário acessar o conteúdo e serviços da aplicação

- Projeto de Interface: A interface oferecida aos usuários é definida.

Geração de página é uma atividade de construção que faz uso de ferramentas automatizadas para criação da aplicação. O conteúdo definido na atividade de Engenharia é combinado aos projetos arquitetural, navegacional e de interface para produzir páginas executáveis. Os testes são realizados para descobrir erros de função e conteúdo, e ajudar a garantir que a aplicação funcionará corretamente em diferentes ambientes (diferentes browsers).

Vale ressaltar que a cada etapa do desenvolvimento, os resultados são avaliados pelo usuário. As mudanças são solicitadas e integradas às próximas etapas do processo incremental. Dessa forma, a preocupação com avaliação é uma premissa constante do desenvolvimento.

Segundo [Olsina et al., 1999], apesar de avaliação de software ter mais de três décadas como disciplina, a avaliação de qualidade de aplicações hipermídia e em particular de websites é uma questão recente e tem sido freqüentemente negligenciada. Somente nos últimos três anos, surgiram avaliações específicas ao domínio [Lohse \& Spiller, 1998], [Nielsen, 2001]. Entretanto, nesta direção, ainda faltam métodos, modelos e ferramentas de avaliação baseados em engenharia, flexiveis e bem definidos, para auxiliar o processo de avaliação de requisitos de qualidade de aplicações Web. 


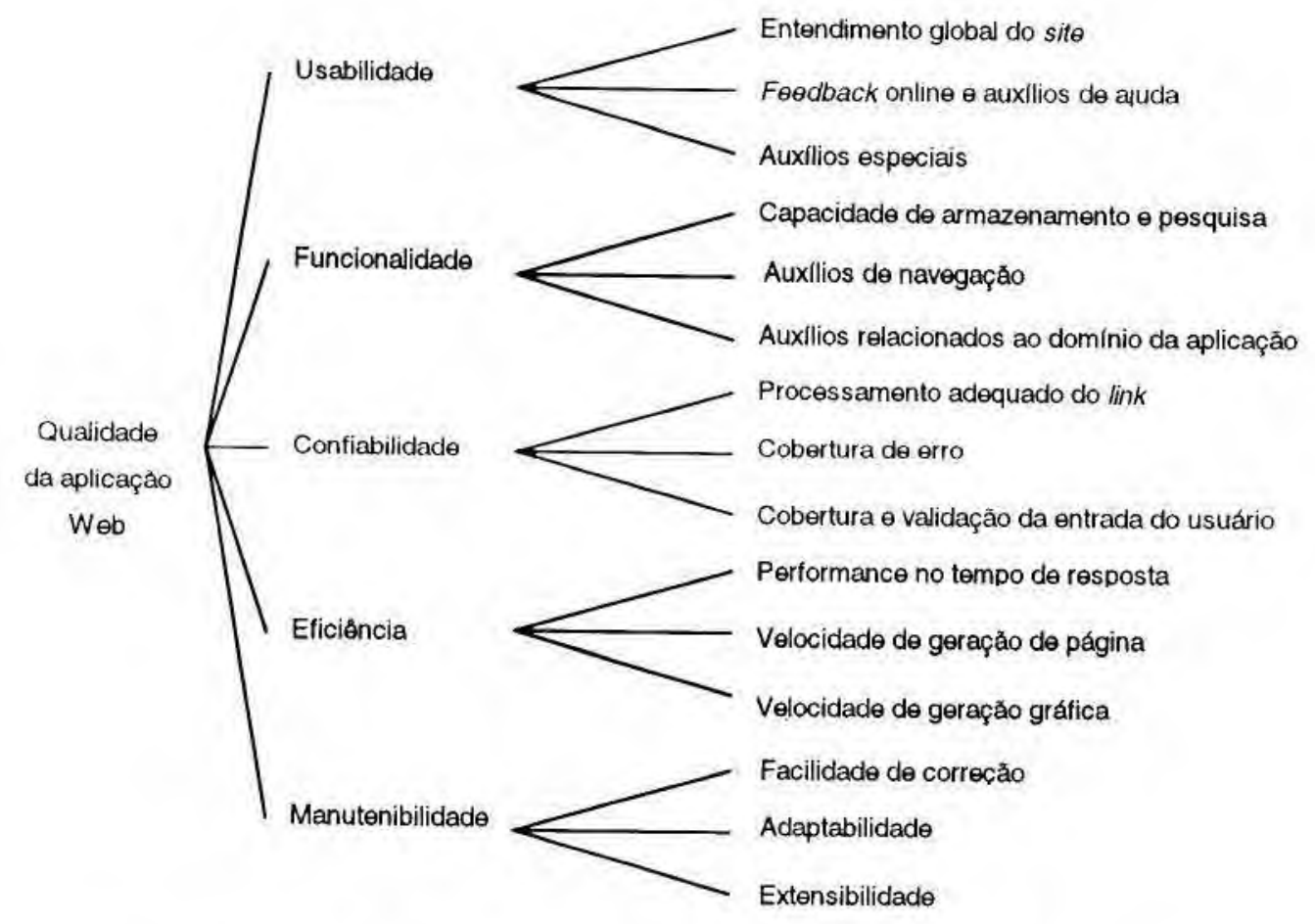

Figura 3. Árvore de requisitos de qualidade para aplicações Web [Pressman, 2000].

Com essa preocupação, [Olsina et al., 1999] definiram uma "árvore de requisitos de qualidade", apresentada na Figura 3, que identifica um conjunto de características que podem servir para verificar se uma aplicação é de alta qualidade e fornecer uma base para que aplicações de qualidade sejam construídas.

[Pressman, 2000] considera como características mais relevantes para aplicações Web, as mesmas de Olsina et al.. Segundo Pressman, essas características fornecem uma base significativa para avaliar a qualidade de aplicações Web. Observa-se que a árvore de requisitos de qualidade somente não contempla o $6^{\circ}$ fator, "portabilidade", que é considerado na norma NBR 13596. Como as aplicações Web em geral se configuram como "independentes de plataforma de hardware", a portabilidade não foi explicitada. Os demais fatores são apresentados, juntamente com suas decomposições específicas relacionadas ao que deve ser observado como possiveis critérios de qualidade.

No trabalho de [Henzinger, 2001] é apresentado um algoritmo para julgar a qualidade de páginas Web a partir de uma análise de links. Henzinger considera que páginas apontadas por muitas outras páginas são de maior qualidade do que páginas apontadas por poucas páginas. Isso significa que o número de links que apontam para uma dada página pode ser usado para medir sua qualidade. No algoritmo (utilizado por Search Engines), a medida de 
qualidade é proporcional à qualidade das páginas que apontam para a página sendo avaliada, se para a obtenção da medida fosse verificado apenas o número de páginas que apontam para a página em avaliação, ficaria fácil aumentar a qualidade da página criando quaisquer outras páginas e inserindo links nessas páginas para a página em avaliação. Como o algoritmo também verifica a qualidade das páginas apontando para a página sendo avaliada, essa possibilidade fica descartada.

\subsection{Considerações Finais}

Neste capítulo foram apresentadas as caracteristicas de qualidade de software, de hipermídia e de aplicações Web. Pode-se observar que são muitos os aspectos que devem ser considerados para a produção de um produto de qualidade e que esses aspectos tanto se relacionam ao processo quanto ao tipo do produto (software, hiperdocumento ou mesmo website).

Entre os diversos aspectos que qualificam um website, durante uma avaliação, um ponto que ainda é pouco mencionado se refere à diversidade tanto de usuários como de domínios de informação. Já na década de 90 , os primeiros esforços para avaliação de hiperdocumentos foram propostos por [Brown, 1990], quando foi destacada a necessidade de ferramentas automáticas para avaliação de caracteristicas inerentes ao hiperdocumento para auxiliar a atividade humana de análise da qualidade de hiperdocumentos. Outros esforços [Hatzimanikatis et al., 1995], posteriormente relatados, indicaram que a experiência prática nas áreas de Engenharia de Software e de Métricas de Software seria útil para a tarefa de análise e avaliação da qualidade de hiperdocumentos.

A utilização de métricas, segundo [Mendes et al., 2001], é uma abordagem apropriada para avaliar a qualidade e o desenvolvimento de aplicações Web, assim como para obter feedback de maneira a auxiliar o entendimento, controle, melhorias, e prognósticos sobre tais produtos e processos.

Por ser o tema mais amplo sobre o qual este trabalho foi realizado, este capítulo apresentou inicialmente uma visão geral de qualidade de software. A seguir, foi descrita qualidade de hipermídia e, finalmente, a qualidade de aplicações Web, que foram propostas na literatura. Neste trabalho, o objetivo foi analisar um conjunto de métricas de hiperdocumentos aplicadas a websites. Essas métricas, que podem ser utilizadas durante todas as fases de desenvolvimento do produto, foram aplicadas a sites existentes como atividade experimental, descrita no Capítulo 5. 
De acordo com [Olsina et al., 1999] e [Pressman, 2000] a qualidade de aplicações Web, como "produto", está mais relacionada às características de: Usabilidade, Funcionalidade, Confiabilidade, Eficiência e Manutenibilidade. Essas características podem ser então fatoradas de maneira a possibilitar que atributos específicos possam ser mensurados. Assim, nos concentramos em métricas objetivas em função de dados automaticamente coletados de websites. Neste trabalho de mestrado, especificamente, foram analisadas métricas de estrutura e de conteúdo.

No próximo capítulo, são apresentadas as métricas estudadas. 


\section{Capítulo 3 - As métricas de hiperdocumentos \\ estudadas}

\subsection{Consideraçôes Iniciais}

De acordo com [Basili et al., 1994], métricas podem ser usadas para:

i. Fornecer as bases para o planejamento de projeto

ii. Determinar os pontos fortes e fracos dos processos e produtos atuais

iii. Fornecer principios para adoção/refinamento das técnicas

iv. Avaliar a qualidade de processos e produtos específicos

v. Avaliar o progresso de um projeto durante seu desenvolvimento

vi. Tomar ações corretivas baseadas na avaliação

vii. Avaliar o impacto da tomada de tal ação

Segundo [Hatzimanikatis et al., 1995], métricas podem ser usadas para entender o processo de autoria hipermídia que visa a construção de vários produtos, tais como, uma especificação, um projeto e uma aplicação hipermídia. O entendimento do processo pode contribuir para seu controle e melhoria. As métricas durante o desenvolvimento de hipermídia têm os seguintes propósitos:

i. Predizer e planejar as próximas fases de um projeto de autoria hipertexto, especialmente teste e manutenção.

ii. Identificar, durante a fase de autoria, as partes de um hiperdocumento que são muito complexas ou mal estruturadas.

iii. Servir como componente de um modelo de qualidade

Neste capítulo são apresentadas métricas de qualidade de hiperdocumentos encontradas na literatura, que foram estudadas em mais detalhes. Essas métricas foram analisadas de forma a auxiliar a seleção de quais poderiam ser implementadas neste trabalho. As razões que determinaram essa seleção são apresentadas no Capítulo 4. 


\subsection{As métricas de hiperdocumentos estudadas}

As primeiras métricas automatizadas para hiperdocumentos foram propostas por [Botafogo \& Shneiderman, 1992]. Elas se baseiam na aplicação de técnicas baseadas em grafos para a obtenção das medidas relativas às métricas de Compactação e Estratificação [Botafogo \& Shneiderman, 1992], que podem ser usadas em uma análise estrutural. De acordo com [Garzotto et al., 1995] as cinco dimensões consideradas pelos autores para analisar uma aplicação hipermídia são: conteúdo, estrutura, apresentação, dinâmica e interação.

Compactação é uma métrica desenvolvida para refletir quão conectada é a estrutura do hiperdocumento.

Definição 1 Seja $H$ um hiperdocumento representado pelo grafo $G=\langle N, L>$, onde $N$ é $o$ conjunto de nós $(|\mathrm{N}|=n)$ e L o conjunto de links. A matriz distância de $H$ é a matriz $A_{n \times n}$ onde:

$a_{i j}=\infty$ (se o nó i não pode ser alcançado pelo nó j) ou

$a_{i j}=\min$ (onde min é o mínimo caminho de $i a_{j}$ )

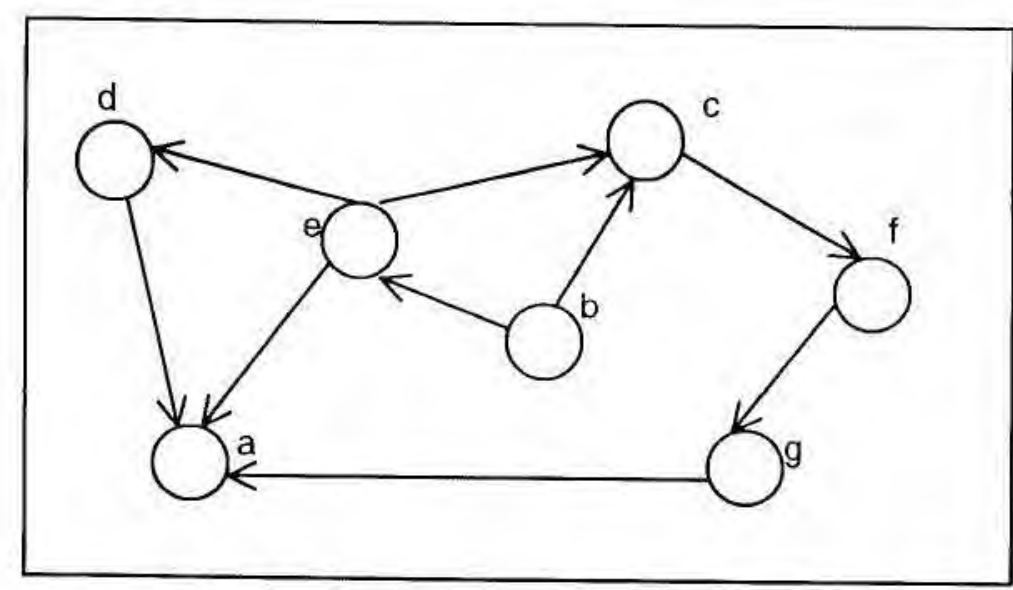

Figura 4. Um grafo representando um hiperdocumento.

Na prática, os valores infinitos são substituidos por um número $\mathrm{K}$ (constante de conversão), resultando na matriz distância convertida. $\dot{E}$ comum escolher $\mathrm{K}$ como o número de nós do hiperdocumento. De acordo com [De Bra, 2000] não é possível executar cálculos simples como tomar a média dos valores na matriz distância devido à ocorrência de $\infty$. Dessa forma, para obter resultados significativos (ou no mínimo finitos), $\infty$ pode ser substituído por um valor chamado constante de conversão. Para evitar interferência entre essa constante e os valores finitos existentes na matriz distância, a constante de conversão precisa ser maior do que o tamanho máximo do caminho mais curto entre dois nós. Por esta razão o número de nós é utilizado. 
Por exemplo, a matriz distância e a matriz convertida do hiperdocumento representado pelo grafo apresentado na Figura 4 são apresentadas na Figura 5.

Figura 5. Matriz distância e matriz distância convertida,

\begin{tabular}{|l|l|l|l|l|l|l|l|}
\hline & $a$ & $b$ & $c$ & $d$ & $e$ & $f$ & $g$ \\
\hline$a$ & 0 & $\infty$ & $\infty$ & $\infty$ & $\infty$ & $\infty$ & $\infty$ \\
\hline$b$ & 2 & 0 & 1 & 2 & 2 & 2 & 3 \\
\hline$c$ & 3 & $\infty$ & 0 & $\infty$ & 1 & 1 & 2 \\
\hline$d$ & 1 & $\infty$ & $\infty$ & 0 & $\infty$ & $\infty$ & $\infty$ \\
\hline$e$ & 1 & $\infty$ & 1 & 1 & 0 & 2 & 3 \\
\hline$f$ & 2 & $\infty$ & $\infty$ & $\infty$ & $\infty$ & 0 & 1 \\
\hline$g$ & 1 & $\infty$ & $\infty$ & $\infty$ & $\infty$ & $\infty$ & 0 \\
\hline
\end{tabular}

\begin{tabular}{|l|l|l|l|l|l|l|l|}
\hline & $a$ & $b$ & $c$ & $d$ & $e$ & $f$ & $g$ \\
\hline$a$ & 0 & 7 & 7 & 7 & 7 & 7 & 7 \\
\hline$b$ & 2 & 0 & 1 & 2 & 2 & 2 & 3 \\
\hline$c$ & 3 & 7 & 0 & 7 & 1 & 1 & 2 \\
\hline$d$ & 1 & 7 & 7 & 0 & 7 & 7 & 7 \\
\hline$e$ & 1 & 7 & 1 & 1 & 0 & 2 & 3 \\
\hline$f$ & 2 & 7 & 7 & 7 & 7 & 0 & 1 \\
\hline$g$ & 1 & 7 & 7 & 7 & 7 & 7 & 0 \\
\hline
\end{tabular}

Definição 2 Seja $H$ um hiperdocumento representado pelo grafo $G=\langle N, L>$, onde $N$ é o conjunto de nós (INI=n), L o conjunto de links e sua matriz distância convertida é $A_{n \times n}^{\prime} . A$ compactação de Hé definida por:

$$
\text { Compactação }=\frac{(\text { Max }- \text { Soma })}{(\text { Max }- \text { Min })}
$$

onde:

$$
\begin{aligned}
& \text { Soma }=\sum_{i=1}^{n} \sum_{j=1}^{n} \mathrm{a}_{\|}^{\prime} \\
& \operatorname{Max}=\left(n^{2}-n\right) * K \\
& \operatorname{Min}=\left(n^{2}-n\right)
\end{aligned}
$$

$a_{i j}^{\prime}=K$ (se o nó $i$ não pode ser alcançado pelo nó $j$ ) ou

$a_{i j}^{\prime}=\min$ (onde min é o mínimo caminho de $i$ a $j$ )

Quando todo nó em um hiperdocumento é isolado, todo elemento $a_{1 j}^{\prime}$ na matriz distância convertida é igual a K (o máximo valor que um elemento pode assumir na matriz distância convertida) para $i \neq j$. Isso significa que a matriz terá $\left(n^{2}-n\right)$ elementos iguais a $K$, conseqüentemente $\operatorname{Max}=\left(n^{2}-n\right) * K$. O valor mínimo de Soma será atingido quando todo nó é conectado aos outros. Quando isso acontece, todo elemento na matriz distância convertida é igual a 1 e, conseqüentemente, Min será igual a $\left(n^{2}-n\right)$. No exemplo anterior, 


$$
\begin{aligned}
\text { Compactação } & =\left[\left(\left(7^{2}-7\right)^{\star} 7\right)-198\right] /\left[\left(7^{2}-7\right)^{\star} 7-\left(7^{2}-7\right)\right] \\
& =(294-198) /(294-42) \\
& =96 / 252 \\
& =0.381 .
\end{aligned}
$$

Se cada nó do grafo é diretamente conectado a todos os outros, a compactação será 1. Por outro lado, se um grafo possui apenas nós isolados terá compactação igual a 0 . Botafogo considera que uma compactação de 0.5 sugere uma estrutura bem conectada mas, obviamente, isso depende do tipo de hiperdocumento que está sendo medido.

Estratificação é uma métrica usada para capturar a ordenação linear do hiperdocumento. Essa métrica reflete as escolhas de navegação do usuário enquanto navega no hiperdocumento. Dependendo do modo como o hiperdocumento é construído, os usuários terão acesso a uma estrutura mais ou menos flexivel de navegação. Um hiperdocumento estratificado não permite muita flexibilidade durante a navegação, ou seja, fornece um modo estratificado ou hierárquico de navegação. Um hiperdocumento com uma alta estratificação indica que os usuários não têm muita escolha e, conseqüentemente, têm menor possibilidade de sofrer com o problema de desorientação. Por outro lado, uma baixa estratificação sugere que o número excessivo de links que o usuário possa escolher pode causar desorientação ao usuário [Fortes \& Nicoletti, 1999].

Definição 3 [De Bra, 1999] Seja $H$ um hiperdocumento representado pelo grafo $G=\langle N, L>$, onde $N$ é o conjunto de nós (INI=n), L é o conjunto de links, e seja $d(u, v)$ a distância mínima do nó u para o nó v na matriz distância. Então

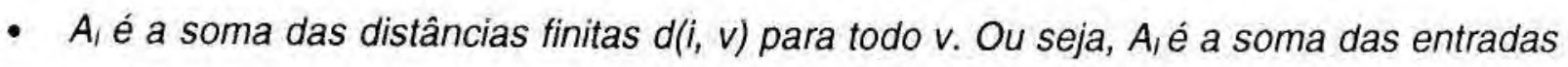
finitas nas i-ésimas linhas da matriz distância. $A_{l}$ é chamado "status" do nó $i$.

- $B_{i}$ é a soma das distâncias finitas $d(u, v)$ para todo $u$. Ou seja, $B_{i}$ é a soma das entradas finitas nas i-ésimas colunas da matriz distância. Bié chamado "contrastatus" do nó i.

- A distância total é a soma de todas as distâncias finitas.

O prestígio do nó i é dado por $A_{1}-B_{1}$. O prestígio total (soma de todos os prestígios) de um hiperdocumento é sempre 0 . O prestígio absoluto (ou estratificação absoluta) é definido como a soma dos valores absolutos do prestígio de cada nó; seu valor obviamente aumenta com o tamanho do hiperdocumento. A Tabela 1 apresenta esses valores para o grafo da Figura 4. Um modo de normalizar o prestígio absoluto é compará-lo ao prestígio de um documento linear do mesmo tamanho. O prestígio absoluto linear (Linear Absolute Prestige - 
LAP) de um hiperdocumento com n nós é o prestígio absoluto de um hiperdocumento linear com n nós, ou seja, se n é o número de nós, LAP é definido como [Papast, 1997]:

$$
L A P=\left\{\begin{array}{l}
n^{3} / 4 \text { se } n \text { div } 2=0 \\
\left(n^{3}-n\right) / 4 \text { se } n \text { div } 2=1
\end{array}\right.
$$

A estratificação de um hiperdocumento é definida como seu prestígio absoluto dividido por seu LAP. [De Bra, 2000] explica que essa métrica consiste da soma (dos valores absolutos) da soma das distâncias de um nó aos outros menos as distâncias desses nós para o nó. Esses números são também chamados de "prestígio absoluto" dos nós e a soma desses é o prestígio absoluto do hiperdocumento. Os fatores de normalização $n^{3} / 4$ e $\left(n^{3}-n\right) / 4$ representam o prestígio absoluto de um documento linear, chamado prestígio absoluto linear (LAP), que é máximo.

Tabela 1. Prestígio e prestígio absoluto para o grafo da Figura 4.

\begin{tabular}{|l|c|c|c|c|}
\hline & $A_{i}$ & $B_{i}$ & Prestígio $_{i}$ & IPrestigio $_{i} \mid$ \\
\hline$a$ & 42 & 10 & 32 & 32 \\
\hline$b$ & 11 & 42 & -31 & 31 \\
\hline$c$ & 27 & 30 & -3 & 3 \\
\hline$d$ & 36 & 31 & 5 & 5 \\
\hline$e$ & 15 & 36 & -21 & 21 \\
\hline$f$ & 31 & 26 & 5 & 5 \\
\hline$g$ & 36 & 23 & 13 & 13 \\
\hline
\end{tabular}

O prestígio absoluto do hiperdocumento, apresentado na Figura 4, é 110. Seu LAP é $\left(7^{3}\right.$ $7) / 4=84$ e a estratificação $110 / 84=1.31$. Infelizmente, até o momento, não há interpretação sobre os valores obtidos com essas métricas.

As métricas de Compactação e Estratificação apresentadas, respectivamente, visam indicar quão conectada é a estrutura do hiperdocumento e a ordenação linear do hiperdocumento.

Outras métricas foram propostas por [Hatzimanikatis et al., 1995], que consideraram os fatores de qualidade, identificados como legibilidade e manutenibilidade de um hiperdocumento. Os critérios correspondentes foram também definidos. Foram apresentadas as métricas de estrutura que podem ser coletadas para subsidiar a avaliação desses critérios, que podem ser computadas a partir do grafo que representa a estrutura do hiperdocumento. A maioria dessas métricas foi derivada das métricas aplicadas a softwares.

Como manutenibilidade e legibilidade não podem ser obtidos diretamente, esses fatores são decompostos em critérios de nível mais baixo, ou seja, são definidos atributos do hiperdocumento que podem ser mais facilmente medidos, além da relação de dependência 
entre os fatores e seus correspondentes atributos. Os critérios são: tamanho, complexidade do caminho, impureza da árvore, modularidade, complexidade individual do nó, coerência, complexidade do conteúdo dos nós e simplicidade. A maioria dos critérios afeta ambos os fatores, manutenibilidade e legibilidade.

As métricas para os critérios de coerência, complexidade do conteúdo do nó e simplicidade não são discutidas em detalhes por Hatzimanikatis et al..

Coerência - possibilidade de fácil percepção de um estilo. Quando existe um estilo coerente de apresentação e estruturação, tornam-se mais claras a leitura e a navegação.

Complexidade do conteúdo dos nós - o tamanho do conteúdo do nó e a quantidade dos diversos tipos de informação, tais como gráficos ou imagens.

Simplicidade - quantidade de efeitos especiais ou botões de controle e o nivel de facilidade para compreensão do conteúdo, da estrutura, e finalmente, do estilo do autor. Muitos efeitos especiais podem atrapalhar a leitura e desviar a atenção do conteúdo real do hiperdocumento. Além disso, é importante para um mantenedor entender o estilo do autor, para garantir a consistência durante a alteração do hiperdocumento.

Interessados em identificar as métricas possiveis de serem automatizadas, Hatzimanikatis et al. utilizam os critérios, focalizando sobre as métricas estruturais para tamanho, complexidade do caminho, impureza da árvore, modularidade e complexidade individual do nó. Para obtenção das medidas das métricas escolhidas são propostas as adequações de métricas de software:

1. Tamanho - o tamanho real do hiperdocumento. Quanto maior o hiperdocumento, maior a possibilidade de desorientação do leitor. Conseqüentemente, torna-se mais difícil compreendê-lo integralmente quando for preciso realizar alguma manutenção.

Para este critério pode ser aplicada a métrica de linhas de código, LOC (lines of code). Essa medida leva em consideração algumas quantidades básicas de um programa, definidas por [Halstead, 1977] como: $\boldsymbol{n}_{1}$ (número de operadores únicos), $\mathbf{n}_{2}$ (números de operandos únicos), $\mathbf{N}_{1}$ (número total de operadores) e $\mathbf{N}_{2}$ (número total de operandos). Com elas, podese calcular:

- Extensão de um programa Ext $=\mathbf{N}_{1}+\mathbf{N}_{2}$,

- Vocabulário $\operatorname{Voc}=\mathbf{n}_{1}+\mathbf{n}_{2}$, 
- Volume $\mathrm{Vol}=$ Ext $\mathbf{x} \log _{2}$ Voc, que é definido como "o número de comparações mentais necessárias para se escrever um programa de extensão Ext".

Ao contrário das outras métricas que serão apresentadas a seguir, a analogia para aplicação dessa métrica na obtenção do tamanho de um hiperdocumento não é direta, mas é sugerido que as palavras-chave que descrevem os nós e os links sejam consideradas como operadores e os conteúdos dos nós, as linhas de texto ou figuras sejam considerados como operandos.

2. Complexidade do caminho - o número de caminhos e ciclos do hiperdocumento. Um hiperdocumento quase linear é facilmente navegado e sua expansão é quase direta. A existência de muitos caminhos de navegação diferentes e um número excessivo de possiveis ciclos aumenta a sobrecarga cognitiva sobre o leitor.

Para este critério, as métricas Compactação e Estratificação propostas por [Botafogo \& Shneiderman, 1992] poderiam ser utilizadas. No entanto, Hatzimanikatis et al. sugerem que as seguintes métricas da área de Engenharia de Software sejam consideradas:

- número ciclomático de um programa (Ncicl) cujo valor é baseado em seu grafo de controle e é usado para medir a complexidade de caminhos de programas. Este número é dado por:

$$
\operatorname{Ncicl}(G)=e-n+p
$$

onde G é o grafo de controle com $\mathbf{n}$ vértices (nós), e arestas (links) e p componentes conexas.

Analogamente, com base no grafo de um hiperdocumento, pode-se obter o seu número ciclomático. No caso de um hiperdocumento estritamente linear, o seu número ciclomático será igual a 1; este número cresce proporcionalmente ao número de caminhos.

- a medida da complexidade das estruturas de dados (CED) definidas nos programas, que se baseia nos caminhos circulares que podem ser encontrados em um grafo e ao mesmo tempo indica o tamanho do grafo. Para seu cálculo, um multigrafo G é produzido a partir das dependências das estruturas de dados de um programa. Para cada componente $\mathrm{K}$ fortemente conexa do grafo é produzido um monômio (polinômio com um único termo) da seguinte forma:

$$
\operatorname{CED}(K)=(n+e) x^{L}
$$


onde $\mathrm{K}$ possui $\mathbf{n}$ nós, e arestas e $\mathbf{L}$ caminhos circulares e $\mathbf{x}$ é a variável do polinômio.

Por analogia, a métrica pode ser aplicada ao grafo de um hiperdocumento. Deve-se observar que, nessa métrica, cada nó e aresta de um componente fortemente conexo aumentam sua complexidade, e o número de círculos ( $L$, expoente do monômio) afeta ainda mais a ordem de magnitude da medida obtida.

3. Impureza da árvore - proporção de desvio do grafo do hiperdocumento quando comparado com uma estrutura do tipo árvore pura (que não possui ciclos). A estrutura de documentos tradicionais impressos é muito semelhante a uma estrutura de árvore pura e, geralmente, pode ser facilmente compreendida tanto pelos leitores como pelos mantenedores.

Para este critério, as métricas Compactação e Estratificação propostas por [Botafogo \& Shneiderman, 1992] poderiam ser utilizadas. No entanto, Hatzimanikatis et al. sugerem a utilização de uma outra métrica da área de Engenharia de Software, a métrica de impureza da árvore [Fenton \& Pfleeger, 1998].

Em Engenharia de Software, acredita-se que quanto maior o desvio da estrutura de um projeto em relaçäo à estrutura de árvore pura, pior é o projeto [Kan, 1995]. [Fenton \& Pfleeger, 1998] apresentam diversas propriedades que a métrica de impureza da árvore $\mathrm{MI}(\mathrm{G})$, para um grafo $\mathrm{G}$, deve satisfazer. Uma métrica satisfatória é dada pelo número de arestas que excedem a extensão da árvore do grafo $\mathrm{G}$ dividido pelo número máximo de arestas que excedem a extensão da árvore.

Sendo e o número de arestas (links) no grafo $\mathrm{G}$ e $\mathrm{n}$ o número de nós, então a medida de impureza (MI) do grafo $\mathrm{G}$, representando o hiperdocumento, em relação a uma árvore é definida pela seguinte expressão:

$$
M I(G)=\frac{2(e-n+1)}{(n-1)(n-2)}
$$

De fato, o grafo é comparado a um grafo completo com o mesmo número de nós. Essa métrica caracteriza precisamente a impureza da ánore do projeto de um sistema, bem como do projeto de um hiperdocumento.

De acordo com [Hatzimanikatis et al., 1995], o desvio de um grafo de um hiperdocumento da estrutura de uma árvore influencia na leitura do hiperdocumento. Navegação em hiperdocumentos estruturados como árvore sem referências cruzadas é muito mais fácil do 
que em hiperdocumentos com muitas referências cruzadas. A estrutura de árvore lembra livros impressos. Um grau de impureza da árvore aceitável depende da aplicação. Os autores acreditam que aplicações tais como manuais online e livros têm um pequeno valor para a impureza da árvore.

4. Modularidade - quão fácil é a identificação das partes independentes no grafo que representa o hiperdocumento. Quando o hiperdocumento pode ser decomposto em partes menores, cada uma delas com objetivos claros, torna-se mais fácil adicionar novos nós e links e modificá-los para corrigir eventuais falhas. Além disso, a modularização é um critério valioso para a legibilidade do hiperdocumento, uma vez que um hiperdocumento bem projetado e estruturado facilita a navegação.

A seguinte métrica pode ser aplicada:

- a complexidade do fluxo de informações (CFI) de um programa (um módulo), dada por:

$$
C F I=E x t(\text { fanin } \times \text { fanout })^{2}
$$

Para o cálculo dessa fórmula, devem ser obtidos os parâmetros fanin definido como o número de fluxos de informação que chegam ao módulo; os procedimentos que chamam o módulo e as estruturas de dados que o módulo lê e fanout definido como o número de fluxos de informação que deixam o módulo, os procedimentos que o módulo chama e as estruturas de dados que o módulo atualiza. Considera-se também que, quanto maior o módulo (sua extensão), mais complexo é o módulo.

A analogia para aplicação dessa métrica na obtenção da medida de modularidade de um hiperdocumento é feita através da definição de fanin como o número de links que levam a um nó e de fanout, como o número de links que partem de um nó. Em relação à extensão, a métrica de tamanho determina como obter sua medida correspondente.

Hatzimanikatis et al. salientam que a modularidade é, provavelmente, o critério mais importante para a manutenibilidade de hiperdocumentos.

5. Complexidade individual do nó - o número de links de entrada e de saída de cada nó. Um grande número de links de saída implica em uma alta sobrecarga cognitiva para o leitor e também significa que qualquer mudança feita neste nó pode afetar muitos outros nós. 
A principal medida consiste do número de links que partem do nó e o número de links que chegam no nó. Se um nó possui muitos links (de entrada ou saída) os autores deveriam considerar a subdivisão do seu conteúdo em outros nós.

A mesma fórmula utilizada para a medida de complexidade do fluxo de informações do hiperdocumento, com base em fanin e fanout, pode então ser usada para a complexidade dos nós individuais, porém sem considerar o fator extensão, pois o tamanho de um nó não contribui para a complexidade individual da sua estrutura. Ao contrário, pode-se argumentar que, no caso de um "grande" nó consistindo de muitas páginas ou contendo uma combinação de vários conteúdos de texto e gráficos é natural a existência de muitos links. Dessa forma, a fórmula:

$$
C l=\frac{(\text { fanin } \times \text { fanout })^{2}}{E x t}
$$

seria mais adequada para a complexidade individual do nó. Finaimente, Hatzimanikatis et al. concluem que experimentos constituem a questão-chave para a aplicação de métricas e, para suportá-los, são necessárias ferramentas flexíveis para a coleta automática dos valores de suas medidas em um hiperdocumento.

\subsection{Considerações Finais}

Este capítulo apresentou as métricas propostas na literatura para hiperdocumentos, que foram estudadas mais detalhadamente neste trabalho.

Para [Basili et al., 1994], métricas, sob o ponto de vista de desenvolvimento de software, podem ser usadas com o propósito de fornecer informações sobre o andamento do processo de desenvolvimento, e um dos objetivos das métricas é retratar os pontos fortes e fracos dos produtos intermediários gerados. Tratando-se de desenvolvimento hipermídia, um dos primeiros estudos foi realizado por [Hatzimanikatis et al., 1995], que considera as métricas com os seguintes objetivos: predizer e planejar as próximas fases de um projeto de autoria hipertexto, especialmente teste e manutenção; identificar, durante a fase de autoria, as partes de um hiperdocumento que são muito complexas ou mal estruturadas; servir como componente de um modelo de qualidade.

Com esses objetivos, Hatzimanikatis et al. definiram um modelo baseado nas idéias do modelo hierárquico FCM e propuseram métricas para hiperdocumentos baseadas em métricas de software conhecidas na literatura [Fenton \& Pfleeger, 1998]. Nem todas as 
métricas propostas podem ser derivadas diretamente para hiperdocumentos, dessa forma, algumas considerações foram feitas pelos autores para sua adequação.

As métricas apresentadas neste capítulo foram estudadas detalhadamente, com o objetivo de possibilitar a determinação de quais poderiam ser implementadas. Assim, foram selecionadas as métricas de Compactação, Estratificação e Impureza da Árvore. No próximo capitulo, é descrita a abordagem que inclui a implementação dessas métricas, considerando-se o auxílio de técnicas de AM. 


\section{Capítulo 4 - A abordagem utilizada para análise das métricas utilizando técnicas de Aprendizado de Máquina}

\subsection{Considerações Iniciais}

Neste capítulo a abordagem proposta para a análise de métricas é apresentada. Essa abordagem utiliza técnicas de Aprendizado de Máquina supervisionado e não supervisionado para auxiliar a análise dos valores obtidos com a aplicação de métricas coletadas de websites.

Para a coleta de métricas foi utilizada uma ferramenta desenvolvida no ICMC-USP. Assim, na Seção 4.2 é descrita esta ferramenta, DB-LiOS, que foi empregada na coleta dos dados necessários para obtenção dos valores das métricas. Na Seção 4.3 são descritas as métricas utilizadas, bem como a forma geral dos algoritmos que foram implementados para coleta das informações necessárias para obtenção dos valores dessas métricas. Na Seção 4.4 é descrito o processo utilizado, contando com o suporte de técnicas de AM, para análise das métricas.

\subsection{Ferramenta DB-LiOS}

A dinâmica e a flexibilidade da autoria de hiperdocumentos na Web, por um lado popularizam a cada dia o uso da Internet, mas por outro, propiciam que facilmente muitas informações fiquem inconsistentes [Seraphim \& Fortes, 2000]. Basta uma definição errônea de um link, para que o usuário se depare com uma inconsistência e se sinta "perdido". Um procedimento comum durante o desenvolvimento de um site é a reutilização dos componentes de link, seja por haver na mesma página-origem mais de um link, ou o mesmo rótulo de link em diversas páginas, ou ainda vários links para uma mesma página-destino. Como um site, geralmente, contém uma grande quantidade de links, torna-se inviável a verificação manual da reusabilidade de seus links. 
A ferramenta DB-LiOS (DataBase - Link Oriented System) foi desenvolvida com o objetivo de proporcionar uma avaliação automática da consistência estrutural de websites através de extração e classificação de seus links, segundo as métricas baseadas em reuso de links [Fortes \& Nicoletti, 1997a]. Além disso, os seguintes critérios foram também adotados em DB-LiOS: consistência (regularidade da aplicação), isto é, avaliação da forma de tratamento de elementos com conceitos similares ou distintos; e reuso, ou seja, a reutilização de objetos e operações em diferentes contextos e para diferentes propósitos. Esses dois critérios definidos em [Garzotto et al., 1995], compõem a abordagem de cinco dimensões que deve ser considerada para se avaliar um hiperdocumento: conteúdo, estrutura, apresentação, dinâmica e interação, conforme mencionado no Capítulo 2. Com a utilização de DB-LiOS, os autores de um site podem obter um auxilio efetivo para avaliação da consistência de seus links.

Os links disponibilizados na Web são os elementos de interação do usuário com o sistema hipertexto (browser), que não são definidos na interface do sistema, mas sim no conteúdo dos nós de um hiperdocumento. Os links, de forma geral, definidos e embutidos nas páginas de um website, definem a estrutura de ligação entre as páginas por meio dos seguintes componentes: 1) página onde se encontra o link ("página-origem"); 2) rótulo que identifica a presença do link na página origem ("âncora"), que pode se constituir de um texto ou mesmo uma imagem; e 3) página para onde o link aponta ("página-destino") que pode ser simplesmente um direcionamento para um outro ponto na própria página ou uma outra página. A partir desses três componentes de links, oito casos que representam as variações de reuso desses componentes foram especificados [Fortes, 1996]:

Link 0 - links que contêm a página-origem diferente em relação a todas as demais páginasorigem do site; contêm âncora diferente em relação a todas as demais âncoras do site; e página-destino diferente em relação às demais páginas-destino do site.

Link 1 - links que, diante de todos os links que direcionam para uma mesma página-destino, contêm a página-origem diferente em relação a todas as demais páginas-origem do site e contêm âncora diferente em relação às demais âncoras do site.

Link 2 - links que, diante de todos os links que apresentam uma mesma âncora, contêm a página-origem diferente em relação a todas as demais páginas-origem do site e contêm página-destino diferente em relação às demais páginas-destino do site.

Link 3 - links que, diante de todos os links que direcionam para uma mesma página-destino com a mesma âncora, contêm a página-origem diferente em relação às demais páginasorigem do site. 
Link 4 - links que, diante de todos os links que apresentam uma mesma página-origem, contêm âncora diferente em relação a todas as demais âncoras do site e contêm páginadestino diferente em relação às demais páginas-destino do site.

Link 5 - links que, diante de todos os links, apresentam mesma página-origem com a mesma página-destino e contêm âncora diferente em relação às demais âncoras do site.

Link 6 - links que, diante de todos os links, apresentam mesma página-origem com mesma âncora e contêm página-destino diferente em relação às demais páginas-destino do site.

Link 7 - links que estão na mesma página-origem com a mesma âncora e direcionam para a mesma página-destino.

Em função de a Web ser simplesmente um enorme repositório de páginas com os seus links embutidos, descritos em tags HTML, pode-se observar que a busca de páginas com as características de reuso de componentes de links requer um processamento não trivial e necessita do suporte de uma Base de Dados. Assim, DB-LiOS se orientou pela adoção de uma Base de Dados para armazenar e processar as informações referentes aos links de um site.

Dois módulos funcionais de DB-LiOS realizam os principais processamentos: a) a extração de links das páginas e b) a classificação dos links. O primeiro módulo, de extração, é composto de um crawler [Cho et al., 1998]. O crawler é um programa autônomo que navega por todas páginas do site através de seus links. Os crawlers são utilizados para diversos fins [Koster, 1995], por exemplo, na coleta de palavras para formação de catálogos de Search Engine [Pinkerton, 1994] (como vistos em AltaVista, Yahoo, WebCrawler e Excite) e coleta de todos os documentos que formam o site para criar cópias espelhos do site [Silva et al., 1999]. Na ferramenta DB-LiOS, a função do crawler é extrair as informações referentes aos componentes do link. página-origem, âncora e página-destino.

À medida que o crawler percorre as páginas de um site, são geradas as instâncias dos links na Base de Dados históricos, que se compõe dos dados estruturais de um site com seus links e respectivas páginas.

Uma característica importante da ferramenta é que considera a freqüente evolução de um site, devido a mudanças nas suas páginas e seus links. Essas mudanças em DB-LiOS podem ser analisadas através de controle de versão do site.

Na próxima seção são apresentadas algumas considerações sobre os dados coletados pela ferramenta DB-LiOS. 


\subsubsection{Considerações sobre os dados coletados pela ferramenta DB-LiOS}

Os dados coletados pela ferramenta DB-LiOS são extraídos por um crawler que foi implementado para extrair os componentes de links das páginas de websites. Nas próximas seções são descritas as considerações sobre como os dados (relacionados com os conceitos de subdiretórios, frames e subdomínios) foram coletados por esse crawler.

\section{Subdiretórios}

O crawler implementado na ferramenta DB-LiOS percorre somente as páginas que estão abaixo da hierarquia de um determinado diretório, pertencente ao servidor de arquivos de um website. Algumas vezes, observou-se que existe interesse em se avaliar os links para um certo conjunto de páginas restritas a um determinado subdiretório. Por exemplo, pode-se adicionar o seguinte endereço de site "http://www.icmc.sc.usp.br/cursos/" (observar a identificação do subdiretório /cursos/) para que DB-LiOS faça a varredura somente das páginas que estão contidas nesse subdiretório e abaixo dele.

\section{Frames}

Os frames são coletados pelo crawler como páginas. Frames são divisões da tela do browser em diversos "quadros". Com isso, é possivel apresentar mais de uma página simultaneamente numa janela do browser. Os frames apresentam vários problemas e coletar a composição exata com que os frames se dispõem no browser em tempo-deexecução é uma tarefa difícil.

[HTML, 1999] considera que é muito fácil colocar frames em páginas; porém, nem todos os usuários gostam do uso de tal recurso. De acordo com [Nielsen, 1996], organizar uma página em frames pode confundir o usuário uma vez que o uso de frames quebra o modelo fundamental do usuário de página Web.

A partir do projeto original de Tim Berners-Lee, segundo [Nielsen, 1996], observava-se uma unificação total de diferentes conceitos em uma única idéia, assim, uma página da Web deveria ser:

- a unidade de informação visualizada pelo usuário na tela

- a unidade de navegação (o que ocorre quando o usuário clica em um link ou ativa uma ação de navegação como um marcador de páginas (bookmark))

- um endereço textual usado para armazenar informação na rede (a URL)

- a informação armazenada no servidor e a unidade de edição do autor (exceto se este trabalha com objetos embutidos como arquivos de imagem que requerem a administração de múltiplos arquivos em uma página) 
O projeto de Tim Berners-Lee considera a página como uma unidade atômica de informação. Frames quebram essa noção e introduzem um novo modo de olhar os dados. Com frames, a visão do usuário é determinada por uma seqüência de ações de navegação ao contrário de uma única ação de navegação.

Assim, a navegação não funciona "corretamente" com frames, segundo Nielsen, uma vez que a unidade de navegação é diferente da unidade de visão. Se o usuário cria um marcador de páginas em seu browser, ele não pode ter a mesma visão de uma página quando segue o marcador numa data posterior à criação, pois o marcador não inclui uma representação do estado dos frames.

Outro aspecto é que as URLs também não funcionam "transparentemente", uma vez que a informação de endereçamento apresentada no topo da tela do browser não constitui uma especificação completa da informação apresentada na tela. Se um autor copia uma URL de forma a incluí-la como um link em uma de suas páginas, então aquele link não levará o usuário para a visão desejada, mas para o estado inicial do conjunto de frames.

Além desses problemas, existem outros relativos à implementação [Nielsen, 1996]: usuários com browsers que não suportam frames; relativos à impressão; problemas de consulta, alguns Search Engines não sabem quais composições de frames incluir como unidades de navegação em seu índice; preferência de usuário, em muitos websites que oferecem aos usuários uma escolha entre versões de sites sem frames e com frames é percebido que a maior parte dos usuários prefere projeto livre de frames; necessidade de um modelo de nó mais rico para nós hipertexto na Web que possam ser suportados por frames, por exemplo, nós compostos.

Mais recentemente, [Nielsen, 1999] reviu alguns problemas relacionados a frames e ponderou que frames não são mais o "desastre" que pareciam na época em que surgiram. Devido a alguns avanços na tecnologia de browsers, foram reduzidos os problemas de navegação, impressão e de utilização de marcadores de páginas. Mas segundo Nielsen existem ainda alguns problemas com frames: as URLs não funcionam "transparentemente" e o uso de frames torna a interação com a página mais difícil.

\section{Subdomínios}

Outra consideração importante é que o crawler não extrai os links de subdomínios de um site, por exemplo, para o site "http://www.icmc.sc.usp.br/" existem alguns subdominios como: "http://nt-labes.icmc.sc.usp.brl", "http://labic.icmc.sc.usp.br/", "http://java.icmc.sc.usp.br/", "http://gbdi.icmc.sc.usp.brl", e seus links não são extraidos pela 
ferramenta DB-LiOS quando iniciamos a extração a partir do site "http://www.icmc.sc.usp.br".

Embora tal consideração seja uma garantia de "escopo" de varredura de um website, potencialmente ela ocasiona uma restrição em sites que adotam particionamento intensivo das informações em subdomínios.

\subsection{As métricas escolhidas}

As métricas utilizadas neste trabalho podem ser divididas em duas categorias: métricas aplicadas a sites e métricas aplicadas a páginas

Na primeira categoria, as métricas podem ser computadas quando é conhecida a estrutura de todo o hiperdocumento Web. As métricas da segunda categoria podem ser computadas quando são conhecidos os dados das páginas da Web.

Ao optarmos pelas métricas de hiperdocumentos Web a serem analisadas, tínhamos em mente as informações disponiveis fornecidas pela ferramenta DB-LiOS. Nós não utilizamos as informações sobre a classificação de links de acordo com os casos de reuso, nos restringimos apenas a informações sobre os componentes de links de cada página de um website extraidos pelo crawler. Dessa forma, com as informações estruturais: páginaorigem, âncora e página-destino, geramos uma matriz de adjacência para representar a estrutura do hiperdocumento Web. A partir dessa matriz, os valores para as métricas de Compactação e Estratificação foram obtidos.

Um exemplo de matriz de adjacência para um hiperdocumento Web é dado na Figura 6, os retângulos representam os nós (páginas) e as setas os links (cujas âncoras podem ser texto ou imagem). A informação fornecida por DB-LiOS é dada na Tabela 2; é a partir dessa informação que a matriz de adjacência é gerada.

Tabela 2. A informação fornecida por DB-LiOS.

\begin{tabular}{|l|c|l|}
\hline \multicolumn{1}{|c|}{ Página-origem } & Áncora & \multicolumn{1}{c|}{ Página-destino } \\
\hline http://www.site.com.br/Principal.html & Aulas & http://www.site.com.br/Aulas.html \\
\hline http://www.site.com.br/Principal.html & <img...Figura.jpg ..> & http://www.site.com.br//nform.html \\
\hline http://www.site.com.br//nform.html & Cursos & http://www.site.com.br/Cursos.html \\
\hline http://www.site.com.br//nform.html & Busca & http://www.busca.com.br \\
\hline http://www.site.com.br/Cursos.html & Outras-disciplinas & http://www.site.com.br/Principal.html \\
\hline
\end{tabular}




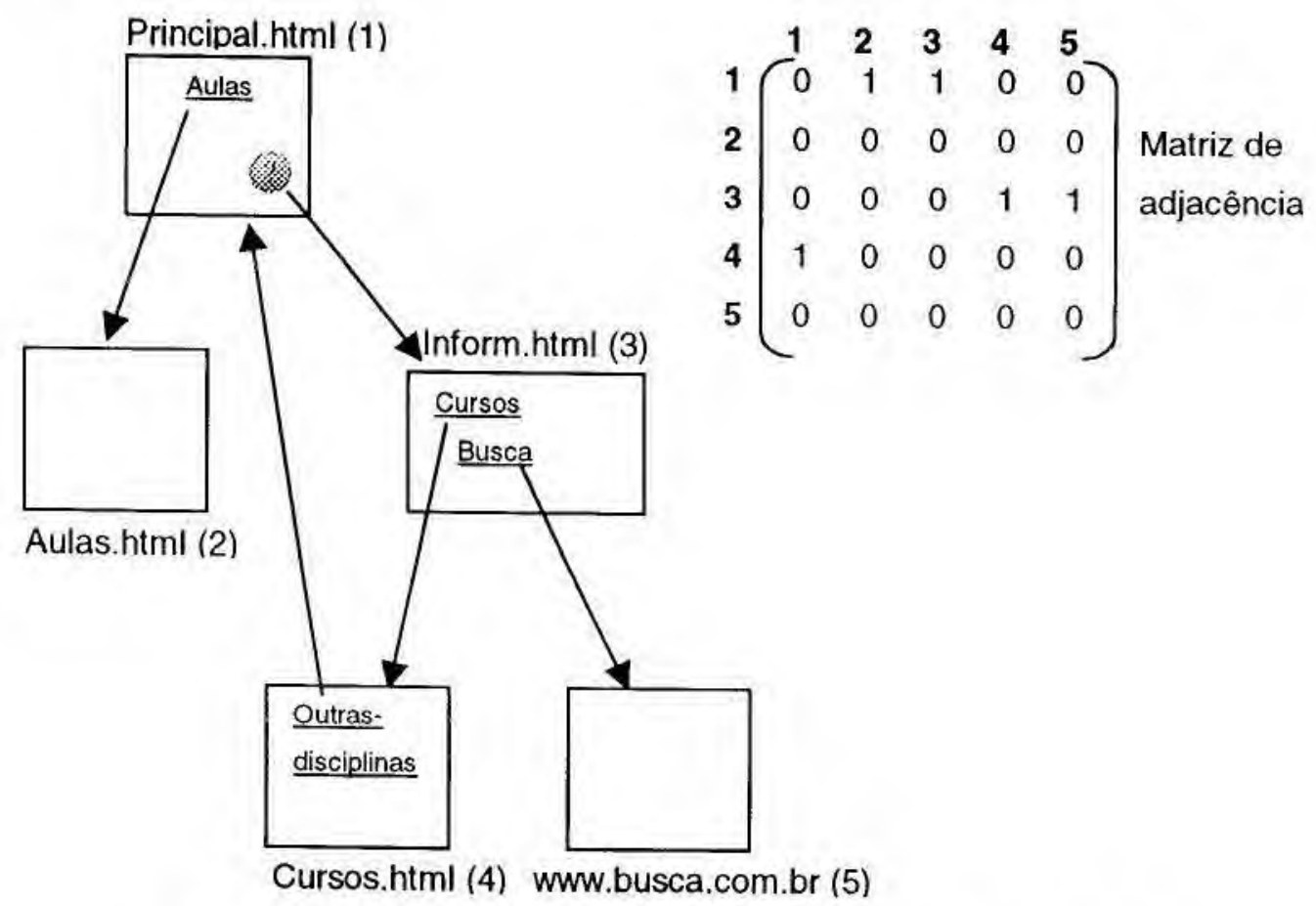

Figura 6. Um hiperdocumento Web e sua matriz de adjacência.

A matriz de adjacência é a base para os cálculos das métricas de Compactação e Estratificação. A partir dessa matriz podemos calcular a matriz distância que é utilizada para obtenção dos valores dessas métricas.

A métrica de Impureza da árvore pode ser obtida diretamente, pois apenas o número de nós (páginas) e arestas (links) são utilizados. Essas informaçōes são fornecidas pela ferramenta após cada varredura.

Como o objetivo deste trabalho foi o de implementar algumas das métricas para realizar a análise com o suporte de técnicas de Aprendizado de Máquina, foram escolhidas algumas das métricas. As métricas que não foram escolhidas são:

Tamanho: pois necessitaria de informações dos conteúdos dos nós (as linhas de texto ou figuras); essa informação não é coletada pela ferramenta DB-LiOS, que coleta informações apenas dos componentes de links como visto anteriormente.

Complexidade do caminho: pois o número de componentes conexas teria que ser calculado, exigindo um algoritmo mais complexo após a coleta dos dados por DB-LiOS; como o objetivo era o de viabilizar a abordagem contando com o suporte de AM, optamos por não implementar o algoritmo para cálculo de componentes conexas, uma vez que requereria um esforço maior. Uma vez definida a abordagem, e experimentalmente testada 
por meio de análise de métricas mais simples, acreditamos que essa métrica poderá vir a ser implementada e analisada com sucesso posteriormente.

Modularidade: a informação sobre o número de links que chegam em um nó (página) não é obtida pela ferramenta DB-LiOS, não há como saber quais sites possuem links para uma determinada página, a não ser que coletássemos todos os sites da Web.

Complexidade individual do nó ( $\mathrm{Cl})$ : necessita também do número de links que chegam no nó.

Além das métricas vistas, propostas por [Botafogo \& Shneiderman, 1992] e [Hatzimanikatis et al., 1995], decidimos coletar informações das páginas dos sites, e assim foram classificadas como "métricas aplicadas a páginas". Essas métricas são: In Links, Out Links, Imagens e Superfície dessas imagens. Seus valores puderam ser obtidos verificando apenas a página-destino e âncora do link. Com a página-destino podemos saber se o link é um link que aponta para uma página de outro site, e com a âncora podemos saber se é uma imagem. Essas métricas aplicadas a páginas são calculadas por meio de contadores que somam as ocorrências de suas características.

Todas essas métricas e a forma de implementação são descritas nas próximas seções.

\subsubsection{Métricas aplicadas a sites}

Nesta seção são apresentados os algoritmos e a forma de implementação das três métricas aplicadas a sites: Compactação, Estratificação e Impureza da Árvore.

A ferramenta DB-LiOS, utilizada neste trabalho para a extração dos links, foi desenvolvida em linguagem Delphi. Os programas que coletam as métricas também foram desenvolvidos em Delphi, utilizando a mesma base de dados da ferramenta DB-LiOS.

Para implementação das métricas de Compactação e Estratificação cada hiperdocumento Web é representado utilizando a matriz de adjacência.

A ferramenta DB-LiOS nos fornece a informação necessária para obter a matriz de adjacência: para cada site tem-se uma lista com todos os links, sendo que esses links são representados por página-origem, âncora e página-destino. A matriz de adjacência é gerada observando-se quais páginas são conectadas por links.

Os algoritmos apresentados a seguir foram utilizados para a obtenção da matriz de mínimo caminho a partir da matriz de adjacência. A matriz de mínimo caminho (ou matriz dos 
caminhos de menor custo) é necessária para os cálculos das métricas de Compactação e Estratificação.

O algoritmo geral utilizado para obter o caminho de menor custo entre dois vértices é esquematizado na Figura 7.

1. Considere um digrafo com pesos associados às arestas

2. Substitua na matriz adjacência os valores ' 1 ' pelos respectivos pesos

3. Obtenha a matriz dos caminhos de menor custo, $M C$, tal que $M C_{i j}=$ custo do menor caminho de $\mathrm{i}$ a j

4. Estratégia

Trocar 0 por $\infty$ e 1 pelo peso na matriz Adjacência $X$ Aplicar o algoritmo de Robert-Ferland

Figura 7. Algoritmo para obtenção da matriz de mínimo caminho.

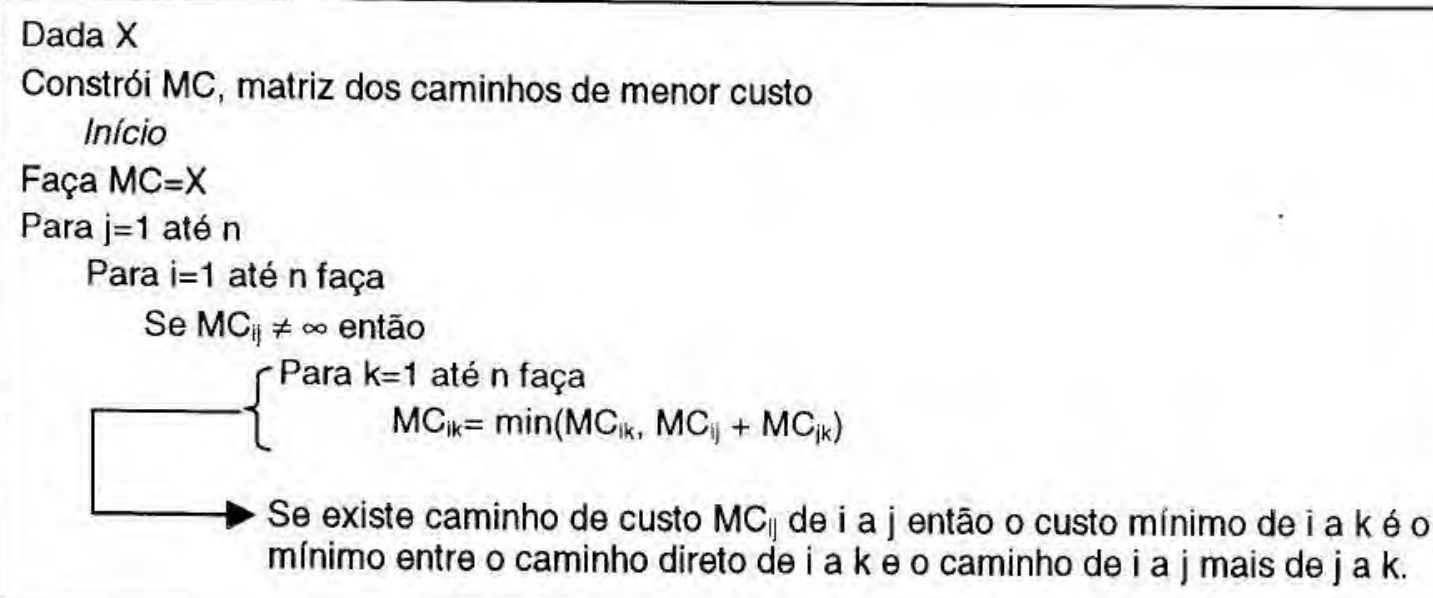

Se existe caminho de custo $\mathrm{MC}_{\|}$de i a j então o custo mínimo de i a ké o mínimo entre o caminho direto de i a $k$ e o caminho de $\mathrm{i}$ a j mais de $\mathrm{j}$ a $\mathrm{k}$.

Figura 8. Algoritmo de Robert-Ferland [Szwarcfiter, 1984].

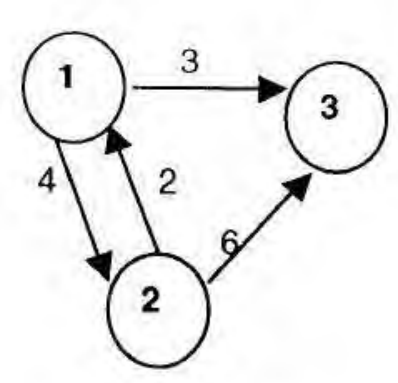

$$
\mathrm{MC}=2\left[\begin{array}{ccc}
1 & 2 & 3 \\
\infty & 4 & 3 \\
2 & \infty & 6 \\
\infty & \infty & \infty
\end{array}\right] \stackrel{\mathrm{RF}}{\longrightarrow} \quad 2\left[\begin{array}{ccc}
1 & 2 & 3 \\
6 & 4 & 3 \\
2 & 6 & 5 \\
\infty & \infty & \infty
\end{array}\right]
$$

Figura 9. Um dígrafo e sua matriz de mínimo caminho.

Um exemplo de matriz de mínimo caminho é ilustrado na Figura 9.

$\mathrm{Na}$ nossa implementação todo peso é igual a 1. Portanto, $\mathrm{MC}_{\text {ij }}$ será o comprimento de menor caminho de $v_{1}$ a $v_{l}$. As matrizes e algoritmos descritos anteriormente foram utilizados para 
implementação dos programas utilizados para obtenção dos valores para as métricas de Compactação e Estratificação.

Para a obtenção do valor da métrica de Impureza da Árvore, apenas os números de nós (páginas) e ligações (links) são utilizados, sendo o valor da métrica obtido diretamente das informações fornecidas pela ferramenta DB-LiOS.

Na próxima seção são apresentadas as métricas aplicadas a páginas.

\subsubsection{Métricas aplicadas a páginas}

As métricas descritas nessa seção necessitam dos dados provenientes das páginas dos sites (nós do grafo), as métricas são: Nro. de links que são imagens, Superfície dessas imagens, Nro. de In Links e Nro. de Out Links. Essas métricas necessitam das informações presentes apenas nos links das páginas, tais como: âncora e página-destino. A ferramenta DB-LiOS, utilizada para extrair os links dos sites fornecidos pelo usuário, procura por links como mostra o exemplo a seguir:

1) $<$ a href= "http://www..." $>$ Pequeno texto $</ a>$

2) $<$ a href="http://www..." $><i m g$ src=" ... gif" width="125" height="78" border="0" $></ a>$

Nesse exemplo as âncoras são respectivamente:

1) Pequeno texto

2) <img src="... gif" width $=" 125$ " height="78" border="0">

O uso de imagens que são âncoras pode ser conveniente porque imagens podem ser de grande ajuda para identificação imediata do propósito do link, mas por outro lado imagens "pesadas" podem ter um grande impacto no sistema. A seguir são apresentadas as métricas implementadas.

\section{Nro. de links que são imagens}

Essa métrica define o número de links que são imagens em uma página. Conforme tem sido observado, com os recursos de multimídia mais disponiveis, a "iconização" para representar direções dos links ou "localização" de mais informação a ser explorada pelo usuário tem se popularizado. Isso é potencialmente bom, pois facilita a leitura para o usuário, mas quando não possui uniformidade, acaba levando à inconsistência e pode desorientar o usuário.

\section{Superfície dessas imagens}

Essa métrica define a superfície total utilizada pelos links que contêm imagens em uma página. A métrica não reflete se as imagens são "pesadas" ou não em termos de espaço em 
memória, ela apenas nos mostra se as imagens ocupam uma quantidade razoável ou não da superfície em tela.

\section{Nro. de In Links}

Número de in links em uma página, ou seja, aqueles links que apontam para uma página do mesmo site do hiperdocumento. In links podem ser muito convenientes porque eles permitem manter o texto "amigável" e local, apresentando a informação de uma maneira acessivel e não restringindo a informação em apenas uma página.

\section{Nro. de Out Links}

Número de out links em uma página, isto é, aqueles links que apontam para páginas fora do site do hiperdocumento. Se o número de out links é alto, então mais cuidado é requerido do mantenedor, pois não há controle "eficiente" no caso desses links apontarem para páginas que podem ser removidas aleatoriamente.

Para obter o número de links que são imagens são percorridas todas as âncoras fornecidas pela ferramenta DB-LiOS, procurando por '<img' na primeira posição da string representando a âncora (veja exemplo anterior).

Quando a âncora é uma imagem, são considerados os valores de width e height e o seguinte cálculo é realizado para obter a superfície utilizada por essas imagens:

$$
\sum_{i=1}^{L} \text { width } \times \text { height }
$$

Onde L é o número de links em de uma página.

Para verificar o número de In Links em cada página, é considerada a string que representa a página-destino e verifica-se se a string contém o site onde a página-origem está localizada.

Para verificar o número de Out Links em cada página, é considerada a string que representa a página-destino e verifica-se se a string não contém o site onde a página-origem está localizada. Portanto aponta para uma página de outro site.

\subsection{Aprendizado de Máquina para auxiliar a análise das Métricas}

As métricas descritas anteriormente foram analisadas com a utilização de técnicas de Aprendizado de Máquina. Em AM existem dois tipos de paradigmas de aprendizado supervisionado e nẫo supervisionado - e a escolha de qual deles usar depende dos exemplos da base, geralmente no formato atributo-valor, estarem ou não rotulados com o 
atributo classe. Quando os dados estão rotulados é possivel utilizar algoritmos de AM supervisionados, os quais induzem conceitos dos dados.

No caso dos dados não estarem explicitamente rotulados com uma classe, é possivel utilizar algoritmos de AM não supervisionados, os quais procuram por padrões nos dados a partir de alguma caracterização de regularidade [Decker \& Focardi, 1995]. Esses padrões são denominados clusters [McCallum et al., 2000] e os exemplos dentro dos clusters são mais similares que exemplos entre clusters. Basicamente, existem três razões de interesse no aprendizado não supervisionado:

(1) a coleção e o rotulamento de um grande conjunto de exemplos podem ser surpreendentemente caros em termos de custo e tempo;

(2) em muitas aplicações as características dos exemplos podem mudar vagarosamente com o passar do tempo;

(3) em alguns estágios da investigação, a descoberta de características pode ser valiosa para adquirir percepções da natureza ou da estrutura de dados.

Mas, apenas agrupar dados de acordo com alguma caracterização de similaridade, conceitualmente, pode ser pouco representativo. Muitas vezes, é de interesse do especialista do domínio tentar encontrar uma "interpretação" ou "explicação" para os dados contidos em cada cluster. Neste trabalho, utilizamos uma metodologia proposta em [Martins \& Monard, 2000] para, através de algoritmos de AM simbólicos, tentar interpretar os clusters obtidos utilizando algum algoritmo de AM não supervisionado. Na próxima seção é descrita a metodologia utilizada.

\subsubsection{Metodologia utilizada}

A metodologia utilizada é ilustrada na Figura 10. Basicamente, a metodologia é composta por quatro etapas. Primeiramente, uma base de dados já processada com exemplos não rotulados, no formato atributo-valor, é submetida a um processamento realizado por algum algoritmo de AM não supervisionado. Esse algoritmo é responsável por descobrir clusters presentes na base de dados. Logo após, o resultado obtido (clusters encontrados) é processado por um mecanismo computável, que rotulará os exemplos da base original, ou um subconjunto desses exemplos, com o cluster ao qual pertencem. Assim é gerada uma base de dados com uma dimensão adicional, a qual é considerada como atributo classe desses exemplos. Essa nova base de dados possui as características necessárias para ser utilizada como entrada para algoritmos de AM supervisionados. Como o interesse principal é tentar explicar clusters previamente encontrados, a linguagem de descrição de conceitos (ou hipóteses) utilizada pelo algoritmo de AM supervisionado escolhido deve ser uma linguagem 
simbólica, tal como regras ou árvores de decisão. Dessa forma, os clusters podem ser descritos, simbolicamente, através de regras ou ámores de decisão.

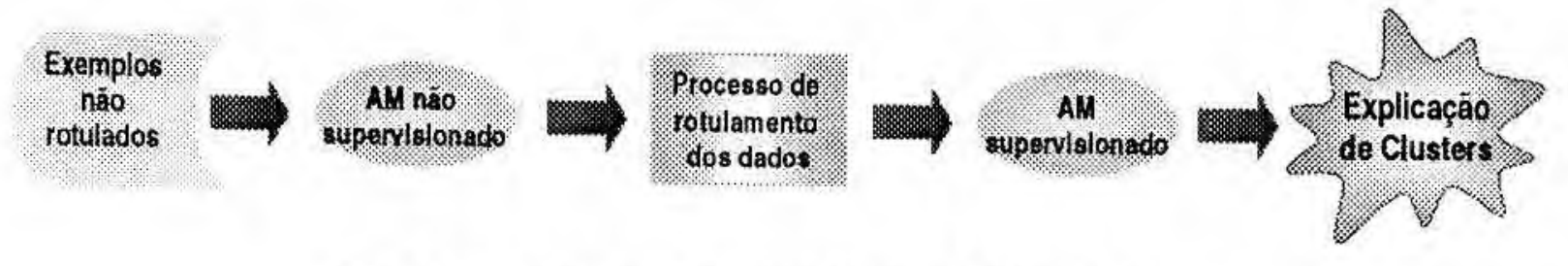

Figura 10. Metodologia utilizada [Martins \& Monard, 2000].

Após essa etapa, o conhecimento do especialista do domínio é de fundamental importância ao se tentar dar uma interpretação semântica aos clusters, agora descritos utilizando outro formalismo. Com a interpretação do especialista é possivel, então, ter uma compreensão e uma "explicação" para os dados pertencentes a cada cluster encontrado.

\subsubsection{Clusters versus Classes}

Esta seção tem como objetivo apresentar a diferença entre cluster e classe, embora esses termos tenham sido usados neste trabalho com o mesmo significado. É importante observar que dois ou mais clusters podem agrupar exemplos que se referem ao mesmo conceito. Isto é ilustrado claramente na Figura 11 que mostra graficamente um conjunto de exemplos de treinamento rotulados com as classes "+" e "-" [Martins et al., 2001].

Após submeter esses exemplos a um algoritmo de AM supervisionado que induz o conceito através de uma árvore de decisão, por exemplo, as regras geradas seriam do tipo:

$$
\begin{aligned}
& \text { if } x<a \text { and } y<b \text { then classe "-" } \\
& \text { if } x \geq a \text { and } y \geq b \text { then classe "-" } \\
& \text { if } x<a \text { and } y \geq b \text { then classe "+" } \\
& \text { if } x \geq a \text { and } y<b \text { then classe "+" }
\end{aligned}
$$

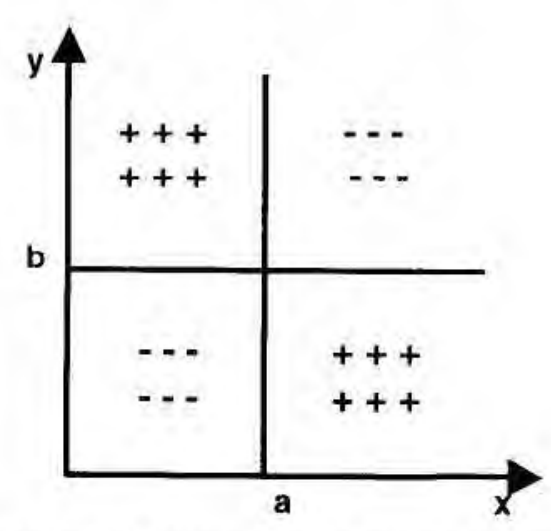

Figura 11. Conjunto de exemplos de treinamento [Martins et al., 2001]. 
Entretanto, no caso de desconhecer a classe, os exemplos de treinamento são vistos pelo algoritmo de clustering como mostra a Figura 12, isto é, apenas como pontos no espaço de busca que podem ser agrupados de acordo com algum critério de similaridade.

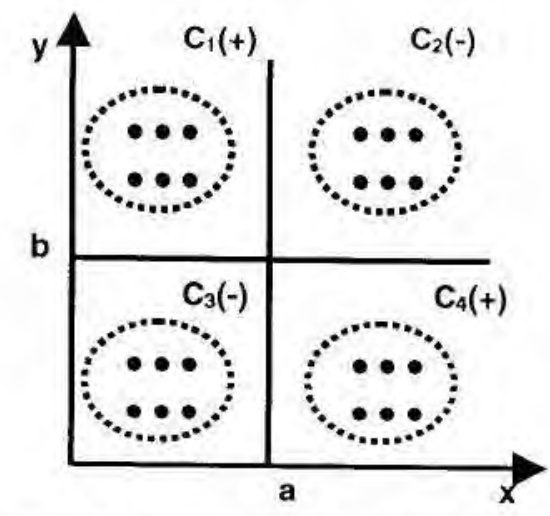

Figura 12. Conjunto de exemplos de treinamento visto pelo algoritmo de clustering [Martins et al., 2001].

Neste caso, o algoritmo de clustering encontra quatro clusters distintos $C_{1}, C_{2}, C_{3}$ e $C_{4}$, Figura 13. Porém, neste conjunto de treinamento há apenas dois conceitos que representam as classes "+" (clusters 1 e 4 ) e "-" (clusters 2 e 3 ).

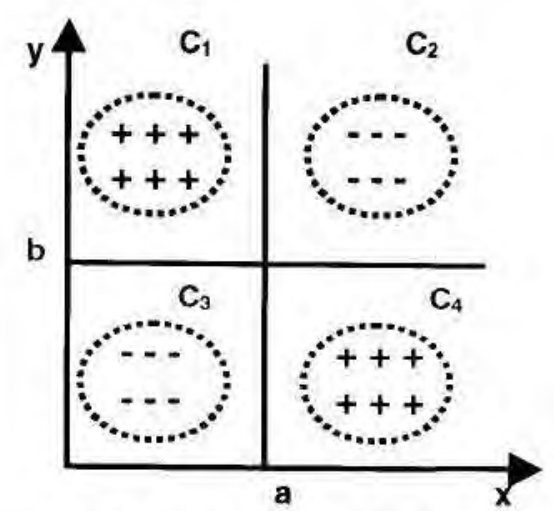

Figura 13. Conjunto de exemplos de treinamento agrupados em clusters [Martins et al., 2001].

Na próxima seção é apresentado o processo utilizado para explicação dos clusters.

\subsubsection{Processo utilizado para Explicação dos Clusters}

Nesta seção é apresentado o processo, ilustrado na Figura 14, que utiliza a metodologia descrita anteriormente, usando o Autoclass como algoritmo de AM não supervisionado. Autoclass é um algoritmo de clustering, baseado na teoria Bayesiana em que o número de clusters pode ser especificado a priori ou encontrado automaticamente pelo próprio algoritmo. A saída gerada consiste de vários relatórios com descrições dos clusters encontrados e a probabilidade parcial dos exemplos nesses clusters. Esses relatórios são 
utilizados na etapa de rotulamento dos exemplos. O processo de rotulamento dos dados é realizado através de uma ferramenta denominada InClass descrita em [Martins \& Monard, 2000]. Essa ferramenta utiliza como entrada um dos relatórios gerados por Autoclass e o conjunto de exemplos originais (não rotulados). A saída gerada por InClass é o conjunto de exemplos contendo agora uma dimensão adicional, pois contém o atributo classe relacionado ao cluster ao qual pertence cada exemplo.

Nesse processo, foi escolhido o See5 como algoritmo de AM supervisionado. See5 utiliza tanto regras quanto árvores de decisão como linguagem de descrição de conceitos. Assim, a base de dados gerada por InClass, no formato requerido por See5, é processada por este para induzir regras de conhecimento. Tomando como base as regras geradas pelo See5, análise de erro e diversas estatísticas, o especialista pode realizar uma análise apurada para tentar explicar o agrupamento dos exemplos nos clusters encontrados.

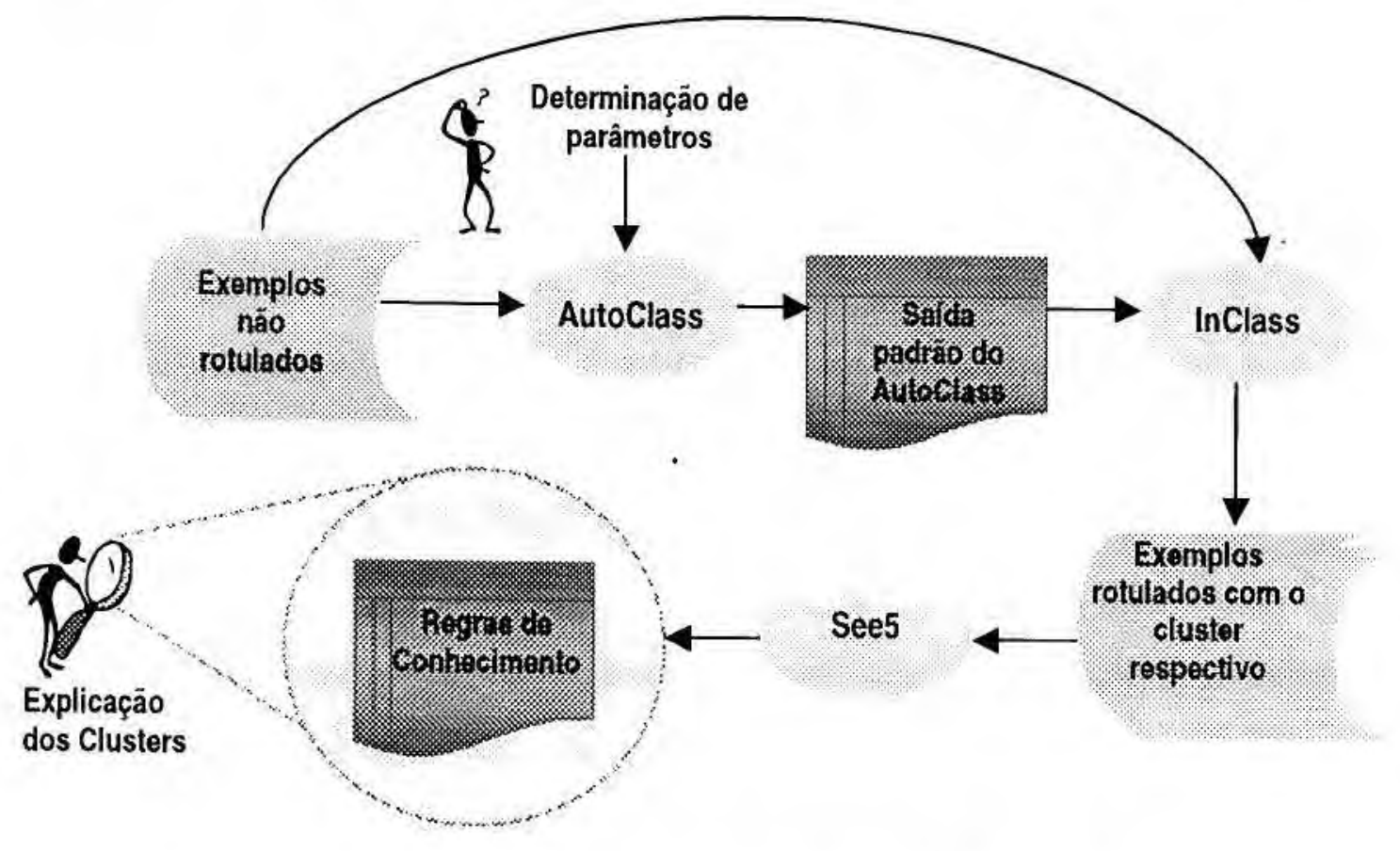

Figura 14. Processo utilizado para explicação dos clusters.

Como descrito pela metodologia, o processo é finalizado com a análise do especialista sobre as regras de conhecimento geradas. É através dessa análise que realmente é possivel verificar se o conhecimento gerado é importante, desconhecido ou útil.

A seguir, são descritas resumidamente as características principais dos algoritmos AutoClass e See5, bem como da ferramenta InClass, utilizados nesse processo. 


\subsubsection{Autoclass}

AutoClass é um algoritmo de aprendizado não supervisionado baseado na teoria Bayesiana, desenvolvido pelo grupo de Bayes no Ames Research Center [Cheeseman \& Stutz, 1990]. Basicamente, AutoClass descreve clusters a partir da distribuição probabilística sobre os atributos dos exemplos, considerando que existe independência condicional nos dados.

AutoClass tem sido usado e testado em muitos conjuntos de dados, pela NASA e pela indústria, meio acadêmico e outras agências. Foram encontradas e mostradas algumas classificações surpreendentes, que mostram padrões nos dados muitas vezes desconhecidos para o especialista da área. AutoClass é um algoritmo robusto e de domínio público, que apresenta, basicamente, as seguintes características:

(1) determina o número de clusters automaticamente ou permite que seja definido pelo usuário;

(2) os valores dos atributos podem ser tanto contínuos quanto discretos;

(3) manipula valores ausentes e desconhecidos;

(4) tempo de processamento é robustamente linear;

(5) gera relatórios descrevendo os clusters encontrados e prediz o cluster de novos exemplos.

AutoClass procura a melhor classificação que possa encontrar nos dados. Uma classificação poderá ser a descoberta de um conjunto de clusters, descrevendo qual a porcentagem provável dos exemplos estarem em cada cluster, e uma denominação probabilística dos exemplos para esses clusters. Isto é, para cada exemplo, a probabilidade relativa de ser membro de cada cluster. A entrada para o algoritmo consiste de um conjunto de dados na forma atributo-valor, definição de modelos e de parâmetros de busca. 0 AutoClass procura um conjunto de clusters que seja altamente provável com os dados e modelos especificados. A saída desse algoritmo é a descrição probabilistica dos clusters identificados e dos exemplos pertencentes a esses clusters, O próprio algoritmo não impõe nenhum limite específico no número de dados, mas bases de dados com mais de 100.000 valores (número de exemplos $x$ números de atributos) podem necessitar de tempo de execução excessivo.

\subsubsection{See5}

See 5 é um produto comercial para plataforma Windows ${ }^{T M}$ que inclui melhorias dos algoritmos C4.5 e C4.5rules [Quinlan, 1993], que têm sido usados, freqüentemente, para comparar seu desempenho com outros algoritmos de AM. O See5 foi projetado para trabalhar com bases de dados relativamente grandes. Como seus precursores, manipula 
atributos com valores discretos e contínuos, induzindo conceitos expressos como árvores de decisão ou conjunto de regras não ordenadas if-then [Baranauskas \& Monard, 2000]. Seu desempenho tem se demonstrado muito bom na maioria dos casos.

\subsubsection{Inclass}

Para que o processo de rotulamento dos exemplos fosse feito de forma automática, utilizamos a ferramenta computacional InClass, descrita em [Martins \& Monard, 2000], implementada na linguagem de programação PERL ${ }^{4}$ [Wall et al., 1996]. Os dados de entrada para a ferramenta são a base de dados original e um dos relatórios gerados pelo AutoClass. Com base nesse relatório do AutoClass e na base de dados original (exemplos não rotulados), o InClass cria uma nova base de dados com os exemplos originais rotulados com o cluster respectivo. Pode-se considerar, na construção da nova base, utilizando InClass, todos os exemplos ou apenas exemplos que pertencem, com uma dada probabilidade, aos clusters encontrados por AutoClass, dependendo dos parâmetros especificados pelo especialista.

\subsection{Considerações Finais}

Neste capitulo foi apresentada a abordagem utilizada para analisar os valores obtidos com a aplicação das métricas.

Essa abordagem engloba seis etapas: utilização da ferramenta DB-LiOS; aplicação dos módulos responsáveis pela obtenção dos valores das métricas de sites e páginas; utilização do Autoclass; utilização do Inclass; utilização do See5 e análise dos resultados.

A ferramenta DB-LiOS foi utilizada para extrair as informações necessárias à coleta dos valores para as métricas. A ferramenta foi desenvolvida com o objetivo de proporcionar uma avaliação automática da consistência estrutural de websites através de extração e classificação de seus links, segundo as métricas baseadas em reuso de links [Fortes \& Nicoletti, 1997a]. Dois módulos funcionais de DB-LiOS realizam os principais processamentos: a extração de links das páginas, a classificação dos links. Neste trabalho apenas o primeiro módulo foi utilizado (o crawler).

Algumas considerações sobre os dados coletados por DB-LiOS também foram destacadas. A ferramenta só extrai os dados abaixo da hierarquia de diretórios, extrai frames como páginas e não extrai os subdomínios de um site.

\footnotetext{
${ }^{4}$ Pratical Extraction and Report Language
} 
Os dados fornecidos por DB-LiOS são então processados pelos módulos responsáveis pela obtenção dos valores das métricas, que neste trabalho, são divididas em duas categorias: métricas aplicadas a sites e métricas aplicadas a páginas.

A abordagem apresentada foi proposta para auxiliar a análise das métricas com o auxílio de técnicas de Aprendizado de Máquina. Essas técnicas têm sido utilizadas freqüentemente no contexto Web.

No próximo capitulo é relatado o experimento realizado seguindo a abordagem descrita. 


\section{Capítulo 5 - 0 experimento realizado utilizando a abordagem proposta}

\subsection{Considerações Iniciais}

Este capitulo apresenta como o experimento, com as métricas de hiperdocumentos Web, foi realizado, utilizando a abordagem descrita no capitulo anterior. O experimento descrito neste capítulo foi realizado com o objetivo de ilustrar e testar preliminarmente a abordagem proposta.

Neste capítulo são relatadas as etapas realizadas: utilização da ferramenta DB-LiOS (Seção 5.2), aplicação dos módulos responsáveis pela obtenção dos valores das métricas de sites e páginas (Seção 5.3), utilização do Autoclass (Seção 5.4), utilização do Inclass (Seção 5.5.), utilização do See5 (Seção 5.6) e análise dos resultados (Seção 5.7). Finalmente, são apresentadas características da infra-estrutura de realização do experimento.

\subsection{As etapas do experimento}

Este experimento segue o processo apresentado no capítulo anterior e foi dividido em seis etapas, sendo essas:

Etapa 1. Utilização da ferramenta DB-LiOS

Etapa 2. Aplicação dos módulos responsáveis pela obtenção dos valores das métricas de sites e páginas

Etapa 3. Utilização do Autoclass

Etapa 4. Utilização do Inclass

Etapa 5. Utilização do See5

Etapa 6. Análise dos resultados

Os dados utilizados no experimento são tabelas no formato atributo-valor, uma com os dados dos sites, utilizando como atributos: Métrica de Compactação, Métrica de Estratificação e Métrica de Impureza da árvore e as outras com os dados das páginas, utilizando como atributos: Nro. de links que são imagens, Nro. de In Links, Nro. de Out Links e Superficie dessas imagens. 
Nas seções seguintes são descritas as etapas do experimento.

\subsubsection{Utilização da ferramenta DB-LiOS}

A ferramenta DB-LiOS foi utilizada para extrair as informações necessárias para aplicação dos módulos responsáveis pela coleta das métricas de sites e páginas. Os sites utilizados no experimento são apresentados na Tabela 3, juntamente com algumas informações adicionais extraídas pela ferramenta DB-LiOS.

Tabela 3. Os sites utilizados no experimento.

\begin{tabular}{|c|c|c|c|}
\hline Número & Site & $\begin{array}{c}\text { Número de } \\
\text { páginas }\end{array}$ & $\begin{array}{c}\text { Número de } \\
\text { links }\end{array}$ \\
\hline 1 & www.ufal.br & 149 & 634 \\
\hline 2 & www.uesb.br & 190 & 601 \\
\hline 3 & www.ufba.br & 1201 & 7889 \\
\hline 4 & www.uece.br & 244 & 771 \\
\hline 5 & www.ufes.br & 858 & 6573 \\
\hline 6 & www.pucsp.br & 40 & 164 \\
\hline 7 & www.unimontes.br & 160 & 366 \\
\hline 8 & www.unisul.rct-sc.br & 94 & 1069 \\
\hline 9 & www.ime.eb.br & 119 & 341 \\
\hline 10 & www.eep.br & 40 & 49 \\
\hline 11 & www.fafica.br & 48 & 171 \\
\hline 12 & www.ufv.br & 956 & 5471 \\
\hline 13 & www.ufpb.br & 56 & 432 \\
\hline 14 & www.ufpe.br & 125 & 708 \\
\hline 15 & www.ita.cta.br & 105 & 3216 \\
\hline 16 & www.ufop.br & 312 & 2828 \\
\hline 17 & www.ufpa.br & 801 & 4235 \\
\hline 18 & www.puc-rio.br & 336 & 3724 \\
\hline 19 & www.puc-campinas.br & 359 & 1210 \\
\hline 20 & www.unaerp.br & 152 & 3544 \\
\hline 21 & www.ufma.br & 171 & 1149 \\
\hline 22 & www.ufmt.br & 77 & 218 \\
\hline 23 & www.ufmg.br & 387 & 3744 \\
\hline 24 & www.ufrj.br & 190 & 2014 \\
\hline 25 & www.icmc.sc.usp.br & 186 & 2654 \\
\hline
\end{tabular}

\subsubsection{Aplicação dos módulos responsáveis pela obtenção dos valores das métricas de sites e páginas}

Os módulos responsáveis por obter os valores das métricas, que foram aplicados aos vinte e cinco sites de universidades brasileiras, são:

(1) Módulo responsável pela obtenção dos dados das páginas de cada site

(2) Módulo responsável pela obtenção dos dados dos sites 
Tabela 4. Algumas páginas e valores para as métricas de páginas do site número 1.

\begin{tabular}{|c|c|c|c|}
\hline \multicolumn{5}{|c|}{ Site 1 } \\
\hline In Links & Out Links & Imagens & Superficie \\
\hline 0 & 0 & 0 & 0 \\
\hline 0 & 1 & 0 & 0 \\
\hline 9 & 0 & 0 & 0 \\
\hline 1 & 1 & 1 & 5396 \\
\hline 3 & 1 & 0 & 0 \\
\hline 4 & 5 & 0 & 0 \\
\hline 10 & 2 & 1 & 4080 \\
\hline 4 & 1 & 1 & 5396 \\
\hline 1 & 0 & 1 & 1250 \\
\hline 0 & 0 & 0 & 0 \\
\hline 1 & 0 & 0 & 0 \\
\hline 4 & 3 & 3 & 12028,67 \\
\hline 3 & 0 & 0 & 0 \\
\hline 11 & 2 & 3 & 225 \\
\hline 34 & 0 & 0 & 0 \\
\hline 1 & 5 & 0 & 0 \\
\hline 10 & 2 & 1 & 4080 \\
\hline 0 & 1 & 1 & 88080 \\
\hline 10 & 1 & 5 & 17183,4 \\
\hline
\end{tabular}

Tabela 5. Os valores obtidos para as métricas de sites.

\begin{tabular}{|c|c|c|c|}
\hline Site & Compactação & Estratificação & $\begin{array}{c}\text { Impureza } \\
\text { da árvore }\end{array}$ \\
\hline 1 & 0.22 & 0.32 & 0.04 \\
\hline 2 & 0.01 & 0.07 & 0.02 \\
\hline 3 & 0.09 & 0.29 & 0.01 \\
\hline 4 & 0.01 & 0.09 & 0.02 \\
\hline 5 & 0.21 & 0.94 & 0.02 \\
\hline 6 & 0.07 & 0.39 & 0.17 \\
\hline 7 & 0.28 & 0.23 & 0.02 \\
\hline 8 & 0.93 & 0.32 & 0.23 \\
\hline 9 & 0.03 & 0.21 & 0.03 \\
\hline 10 & 0.03 & 0.19 & 0.01 \\
\hline 11 & 0.26 & 0.41 & 0.11 \\
\hline 12 & 0.11 & 0.15 & 0.01 \\
\hline 13 & 0.06 & 0.30 & 0.25 \\
\hline 14 & 0.16 & 0.59 & 0.08 \\
\hline 15 & 0.46 & 1.39 & 0.58 \\
\hline 16 & 0.51 & 1.17 & 0.05 \\
\hline 17 & 0.14 & 0.59 & 0.01 \\
\hline 18 & 0.55 & 0.58 & 0.06 \\
\hline 19 & 0.04 & 0.13 & 0.01 \\
\hline 20 & 0.79 & 0.23 & 0.30 \\
\hline 21 & 0.29 & 0.94 & 0.07 \\
\hline 22 & 0.06 & 0.25 & 0.05 \\
\hline 23 & 0.06 & 0.20 & 0.05 \\
\hline 24 & 0.86 & 0.66 & 0.10 \\
\hline 25 & 0.23 & 1.10 & 0.15 \\
\hline
\end{tabular}


Aplicando-se o módulo (1) obtemos uma tabela para cada site, com os seguintes dados: Nro. de In Links, Nro. de Out Links, Nro. de links que são imagens e Superfície dessas imagens. A Tabela 4 apresenta alguns dos valores obtidos com a aplicação deste módulo para algumas das 149 páginas do site número 1.

Aplicando-se o módulo (2) obtemos uma tabela, com os seguintes dados: Compactação, Estratificação, Métrica de Impureza da árvore. A Tabela 5 apresenta os valores obtidos com a aplicação desse módulo aos 25 sites.

A próxima etapa do experimento é a utilização do Autoclass, descrita na próxima seção.

\subsubsection{Utilização do Autoclass}

Após o uso da ferramenta para a coleta dos dados, os mesmos foram preparados para a utilização do Autoclass. Como já mencionado, o Autoclass é responsável por descrever clusters a partir da distribuição probabilística sobre os atributos dos exemplos. A Tabela 6 apresenta um dos relatórios gerados pelo Autoclass, o qual é utilizado por Inclass, na próxima etapa, para rotular os exemplos.

Tabela 6. Um dos resultados do Autoclass.

\begin{tabular}{|c|c|c|}
\hline Site & Classe & Probabilidade \\
\hline 1 & Classe_0 & 1.000 \\
\hline 2 & Classe_0 & 1.000 \\
\hline 3 & Classe_1 & 0.999 \\
\hline 4 & Classe_0 & 1.000 \\
\hline 5 & Classe_0 & 1.000 \\
\hline 6 & Classe_0 & 1.000 \\
\hline 7 & Classe_0 & 1.000 \\
\hline 8 & Classe_0 & 1.000 \\
\hline 9 & Classe_0 & 1.000 \\
\hline 10 & Classe_1 & 0.999 \\
\hline 11 & Classe_0 & 1.000 \\
\hline 12 & Classe_1 & 1.000 \\
\hline 13 & Classe_0 & 1.000 \\
\hline 14 & Classe_0 & 1.000 \\
\hline 15 & Classe_0 & 1.000 \\
\hline 16 & Classe_0 & 1.000 \\
\hline 17 & Classe_1 & 0.994 \\
\hline 18 & Classe_0 & 1.000 \\
\hline 19 & Classe_1 & 1.000 \\
\hline 20 & Classe_0 & 1.000 \\
\hline 21 & Classe_0 & 1.000 \\
\hline 22 & Classe_0 & 1.000 \\
\hline 23 & Classe_0 & 1.000 \\
\hline 24 & Classe_0 & 1.000 \\
\hline 25 & Classe_0 & 1.000 \\
\hline & \multicolumn{2}{|c}{} \\
\hline
\end{tabular}




\subsubsection{Utilização do Inclass}

Utilizando Inclass para o conjunto de dados apresentado na Tabela 6, obtemos o resultado apresentado na Tabela 7, no formato requerido por See5.

Tabela 7. Resultado do Inclass.

\begin{tabular}{|c|c|c|c|c|}
\hline Site & Compactação & Estratificação & $\begin{array}{c}\text { Impureza da } \\
\text { árvore }\end{array}$ & Classe \\
\hline 1 & 0.22 & 0.32 & 0.04 & Classe_0 \\
\hline 2 & 0.01 & 0.07 & 0.02 & Classe_0 \\
\hline 3 & 0.09 & 0.29 & 0.01 & Classe_1 \\
\hline 4 & 0.01 & 0.09 & 0.02 & Classe_0 \\
\hline 5 & 0.21 & 0.94 & 0.02 & Classe_0 \\
\hline 6 & 0.07 & 0.39 & 0.17 & Classe_0 \\
\hline 7 & 0.28 & 0.23 & 0.02 & Classe_0 \\
\hline 8 & 0.93 & 0.32 & 0.23 & Classe_0 \\
\hline 9 & 0.03 & 0.21 & 0.03 & Classe_0 \\
\hline 10 & 0.03 & 0.19 & 0.01 & Classe_1 \\
\hline 11 & 0.26 & 0.41 & 0.11 & Classe_0 \\
\hline 12 & 0.11 & 0.15 & 0.01 & Classe_1 \\
\hline 13 & 0.06 & 0.30 & 0.25 & Classe_0 \\
\hline 14 & 0.16 & 0.59 & 0.08 & Classe_0 \\
\hline 15 & 0.46 & 1.39 & 0.58 & Classe_0 \\
\hline 16 & 0.51 & 1.17 & 0.05 & Classe_0 \\
\hline 17 & 0.14 & 0.59 & 0.01 & Classe_1 \\
\hline 18 & 0.55 & 0.58 & 0.06 & Classe_0 \\
\hline 19 & 0.04 & 0.13 & 0.01 & Classe_1 \\
\hline 20 & 0.79 & 0.23 & 0.30 & Classe_0 \\
\hline 21 & 0.29 & 0.94 & 0.07 & Classe_0 \\
\hline 22 & 0.06 & 0.25 & 0.05 & Classe_0 \\
\hline 23 & 0.06 & 0.20 & 0.05 & Classe_0 \\
\hline 24 & 0.86 & 0.66 & 0.10 & Classe_0 \\
\hline 25 & 0.23 & 1.10 & 0.15 & Classe_0 \\
\hline & & & & \\
\hline
\end{tabular}

\subsubsection{Utilização do See5}

Esse conjunto de exemplos é utilizado por See5 para induzir um conjunto de regras não ordenadas if-then. $O$ conjunto de regras induzidas por See5 foi então analisado para tentar encontrar um significado semântico para o nome dos clusters. Na próxima seção são descritos os resultados obtidos.

\subsubsection{Análise dos resultados}

Nesta seção são apresentados os resultados do experimento. Esse experimento foi realizado em duas etapas, uma com os dados das páginas e outra com os dados de sites. As próximas seções apresentam os resultados obtidos em ambas etapas do experimento. 


\subsubsection{Experimento com os dados das páginas}

O experimento realizado com os dados coletados das páginas não ofereceu resultados muito significativos. $\mathrm{O}$ atributo presente na maioria das regras e com maior importância foi o atributo Superfície das imagens, que indica a superfície utilizada pelas imagens em uma dada página. Futuramente, pretendemos realizar outras experiências com esses dados, utilizando indução construtiva que permite criar novos atributos como uma combinação dos atributos existentes [Russel \& Norvig, 1995].

\subsubsection{Experimento com os dados de sites}

A base de dados de todos os sites foi submetida ao Autoclass sem fixar um número de clusters, tendo sido encontrados 2 clusters. A Tabela 8 apresenta um resumo dos resultados obtidos, onde:

- Clusters - representa os clusters;

- \# Exemplos - número de exemplos na base de dados;

- \% Classe - porcentagem de exemplos pertencentes ao cluster,

- Erro aparente - erro aparente de See5, isto é, utilizando toda a base de dados de treinamento e teste;

- Erro verdadeiro (10CV) - erro verdadeiro obtido através de $10 \mathrm{k}$-fold cross-validation;

- Erro CM - erro da classe majoritária;

- \# Regras - número de regras encontradas por See5;

- \# Médio Regras - número médio de regras obtido nas 10 execuções de cross-validation.

Tabela 8. Experimento com todos os sites-Resumo dos resultados.

\begin{tabular}{|cccccccc|}
\hline $\begin{array}{c}\# \\
\text { Exemplos }\end{array}$ & Clusters & $\begin{array}{c}\% \\
\text { Classe }\end{array}$ & $\begin{array}{c}\text { Erro } \\
\text { Aparente }\end{array}$ & $\begin{array}{c}\text { Erro (10 CV) } \\
\text { Verdadeiro }\end{array}$ & Erro CM & $\begin{array}{c}\# \\
\text { Regras }\end{array}$ & $\begin{array}{c}\text { \# Médio } \\
\text { Regras }\end{array}$ \\
\hline \hline 25 & $\mathrm{C}(0)$ & $80 \%$ & $0,0 \%$ & $0,0 \% \pm 0,0 \%$ & $20 \%$ & 2 & $2 \pm 0$ \\
& $\mathrm{C}(1)$ & $20 \%$ & & & & \\
\hline
\end{tabular}

$$
\begin{array}{ll}
\text { Rule 1: }(\text { cover 20) } & \text { Rule 2: (cover 5) } \\
\text { Impureza da árvore }>0.01 & \text { Impureza da árvore }<=0.01 \\
\rightarrow>\text { classe Classe_0 [0.955] } & \rightarrow \text { classe Classe_1 [0.857] }
\end{array}
$$

Figura 15. Regras extraidas para todos os sites.

As regras obtidas são apresentadas na Figura 15. É importante notar que essas regras classificam os exemplos de acordo com o atributo Impureza da árvore. Impureza da árvore é um critério que influencia a legibilidade de hiperdocumentos. Navegação em um 
hiperdocumento com estrutura de árvore é mais fácil que navegação em hiperdocumentos com muitas referências cruzadas.

A segunda regra classifica cinco sites com um valor menor ou igual a $0.01 \quad(20 \%$ dos exemplos). Os outros sites são classificados pela primeira regra (Impureza da ánore maior que 0.01). Nessas regras aparece apenas o atributo Impureza da árvore, o que indica que somente esse atributo consegue diferenciar os exemplos (sites) considerados.

\subsection{Características da infra-estrutura de realização do experimento}

O experimento, como descrito nesta seção, foi dividido nas seis etapas descritas. A primeira etapa foi a que requereu mais tempo, pois as dificuldades na procura por sites "apropriados" para o experimento e na coleta de seus dados da WWW foram freqüentes. Entendendo por sites "apropriados" aqueles que possuiam um número mínimo de páginas (40), pois os algoritmos de Aprendizado de Máquina requerem um número razoável de exemplos para obter bons resultados, e que não esgotassem um tempo de espera de duas horas na coleta. Enfrentamos também problemas na rede do Instituto e dessa forma, a coleta dos dados tomou um tempo maior do que o esperado.

O número inicial de sites que pensamos avaliar era de 50 sites, mas decidimos trabalhar com os 25 apresentados na Tabela 3, devido ao grande consumo de tempo requerido, além de razões relativas a freqüentes problemas de rede.

Utilizando DB-LiOS, obtivemos os dados necessários para a segunda etapa. Com os dados necessários para a coleta dos valores das métricas, a segunda etapa foi realizada conforme o esperado, utilizando os módulos responsáveis pelos cálculos e obtenção dos valores para as métricas. Esses módulos foram implementados em Delphi para facilitar a manipulação da base de dados gerada por DB-LiOS. Para a implementação dos novos módulos foi necessário primeiramente entender a implementação da ferramenta DB-LiOS.

Os valores calculados, utilizando os módulos implementados, foram então armazenados em 26 tabelas, sendo que uma com os valores calculados de todos os sites e as outras com os dados das páginas de cada site. Os dados contidos nessas tabelas foram então preparados para a utilização do Autoclass.

Autoclass requer alguns arquivos para sua execução, tais como arquivos de dados, arquivos de definições de tipos, etc. Esses arquivos foram criados para execução do algoritmo. Executamos Autoclass sem fixar um número de clusters. 
Com os resultados do Autoclass, executamos o Inclass para que os dados pudessem ser fornecidos ao See5. Para executar o Inclass, os arquivos de entrada foram também preparados, ou seja, todas as tabelas tiveram que sofrer uma reformatação. O See5 também requer alguns arquivos adicionais de definições de tipos de dados além do arquivo resultante de Inclass. Executando See5 obtemos as regras para a análise dos resultados finais. Nessas regras apareceu apenas o atributo Impureza da árvore, o que indica que somente esse atributo conseguiu diferenciar os exemplos (sites) considerados.

Todo o experimento foi realizado contando apenas com esta mestranda, utilizando um único computador.

\subsection{Considerações Finais}

As métricas estudadas, escolhidas e apresentadas, foram implementadas neste trabalho. Em geral, essas métricas tiveram dados inicialmente obtidos a partir das informações fornecidas pela ferramenta DB-LiOS.

Para a realização do experimento, os dados coletados por DB-LiOS tiveram que ser 'processados' de forma a representar as métricas escolhidas. Dessa forma, foram desenvolvidos módulos adicionais para processamento das estruturas de dados e computação das métricas. Com os módulos pudemos coletar os valores das métricas e com o auxilio de técnicas de Aprendizado de Máquina realizamos a análise na qual verificamos que apenas a métrica Impureza da árvore consegue diferenciar os exemplos (sites) considerados. Experimentos com uma quantidade maior de dados poderiam ser realizados para verificar se as regras obtidas representam realmente a situação de sites considerando a métrica Impureza da árvore. 


\section{Capítulo 6 - Conclusões}

\subsection{Conclusões e Contribuições}

O avanço da Web tornou a atividade de construção de hiperdocumentos amplamente praticada. Como essa atividade lida com a manipulação de muitos nós e links, se não for abordada sistemática e cuidadosamente, pode gerar muitos problemas de qualidade no produto (website).

Um produto de qualidade é, geralmente, o objetivo principal de um processo "produtivo" de desenvolvimento. Neste trabalho foi focalizado o tema "qualidade" sob a perspectiva de software, de hipermídia e de hiperdocumentos Web. Foi verificado que, para se alcançar o objetivo de se obter um produto com qualidade, a aplicação de métricas é uma das atividades consideradas. A utilização de métricas, segundo [Mendes et al., 2001], é uma abordagem apropriada para avaliar a qualidade e o desenvolvimento de aplicações Web, assim como para obter feedback de maneira a auxiliar o entendimento, controle, melhorias, e prognósticos sobre tais produtos e processos.

Neste trabalho, estudamos as métricas propostas na literatura para hiperdocumentos e selecionamos algumas para implementação. Como os valores das métricas são de difícil interpretação por parte dos webmasters, apresentamos uma abordagem para auxiliar a análise dos resultados. Tal abordagem conta com auxilio de técnicas de Aprendizado de Máquina, uma subárea de IA que tem sido muito explorada no contexto Web.

A abordagem proposta, descrita no Capitulo 4, engloba seis etapas: (1.) utilização da ferramenta DB-LiOS; (2.) aplicação dos módulos responsáveis pela obtenção dos valores das métricas de sites e páginas; (3.) utilização do Autoclass; (4.) utilização do Inclass; (5.) utilização do See5 e (6.) análise dos resultados.

$\mathrm{Na}$ primeira etapa a ferramenta DB-LiOS foi utilizada para extrair as informações necessárias à coleta dos valores para as métricas. DB-LiOS possui dois módulos funcionais: o primeiro para extração de links das páginas e um segundo, para classificação dos links. Neste trabalho apenas o primeiro módulo foi utilizado (o crawler). Algumas considerações 
sobre os dados coletados por DB-LiOS também foram destacadas. A ferramenta só extrai os dados abaixo da hierarquia de diretórios, extrai frames como páginas e não extrai os subdomínios de um site.

Os dados fornecidos por DB-LiOS são processados, seguindo a segunda etapa da abordagem proposta, pelos módulos responsáveis pela obtenção dos valores das métricas. Neste trabalho, as métricas selecionadas são divididas em duas categorias: métricas aplicadas a sites e métricas aplicadas a páginas, conforme descritas no Capítulo 4.

As etapas (3.), (4.) e (5.) do experimento realizado, seguindo a abordagem proposta, foram descritas no Capítulo 5. Para a realização do experimento, os dados coletados por DB-LiOS tiveram que ser 'processados' de forma a representar as métricas escolhidas. Dessa forma, foram desenvolvidos módulos adicionais para processamento das estruturas de dados e computação das métricas. Com os módulos, pudemos coletar os valores das métricas e, utilizando o processo descrito, com o auxílio de técnicas de Aprendizado de Máquina, realizamos a análise na qual verificamos que a métrica Impureza da árvore consegue diferenciar os exemplos (sites) considerados.

Finalmente, ainda como parte deste trabalho, foi redigido um artigo para conferência, que aceito para publicação, será apresentado em 10 de setembro próximo em Buenos Aires, Argentina [Silva \& Fortes, 2001].

\subsection{Trabalhos Futuros}

Como o experimento realizado com os dados coletados das páginas não ofereceu resultados muito significativos (pois a métrica que calculava a "Superfície das imagens", presente na maioria das regras, somente possibilitou a interpretação de inclusão ou não de imagens nas páginas), futuramente, outras experiências com esses dados devem ser realizadas, utilizando, por exemplo, indução construtiva que permite criar novos atributos como uma combinação dos atributos existentes [Russel \& Norvig, 1995], e dessa forma tentar obter melhores (mais significativos) resultados.

As regras obtidas com a realização do experimento com os dados coletados de sites indicaram que apenas a métrica "Impureza da árvore" consegue diferenciar os exemplos (sites) considerados. Experimentos com uma quantidade maior de dados devem ser realizados para verificar, com um número mais representativo estatisticamente, se as regras obtidas realmente confirmam a situação dos sites existentes. 
A implementação de outras métricas também deve ser considerada. A métrica "Complexidade do caminho", por exemplo, não foi implementada, pois o número de componentes conexas teria que ser calculado, exigindo um algoritmo mais complexo após a coleta dos dados por DB-LiOS; o que desviaria do objetivo deste trabalho, de viabilizar a abordagem contando com o suporte de AM. Uma vez definida a abordagem, e experimentalmente testada por meio de análise de métricas mais simples, acreditamos que essa métrica, assim como outras, possam vir a ser implementadas e analisadas com sucesso.

DB-LiOS armazena informações sobre a evolução dos sites coletados, ou seja, as versões dos sites. Com essas informações podemos realizar a coleta das métricas e um acompanhamento dos seus valores, de forma evolutiva, contribuindo então para uma melhoria ou adequação na definição das métricas e para verificação de como a evolução dos sites influencia os valores dessas métricas. 


\section{Bibliografia}

[Baranauskas \& Monard, 2000] BARANAUSKAS, J. A.; MONARD, M. C.: "Reviewing some machine learning concepts and methods". Relatório Técnico do ICMC, n.102. ftp://ftp.icmc.sc.usp.br/pub/BIBLIOTECA/rel-tec/Rt_102.ps.zip.

[Basili et al., 1994] BASILI, V.; CALDIERA, G. \& ROMBACH, D.: "The Goal Question Metric Approach", Encyclopedia of Software Engineering, Wiley (1994).

[Botafogo \& Shneiderman, 1992] BOTAFOGO, R. A.; SHNEIDERMAN, B. (1992): "Structural Analysis of Hypertexts: Identifying Hierarchies and Useful Metrics" ACM Transactions on Information Systems, v.10, n.2, p.142-80, Abril.

[Brown, 1990] BROWN, P. J. (1990): "Assessing the quality of Hypertext documents" In Rizs, A.; Stritz, N.; André, J.; eds. "Hypertext: Concepts, System and Applications" Cambridge, Great Britain, Cambridge University Press. Proceedings of ECHT'90, p.1-12, Versailles, France, Novembro.

[Cheeseman \& Stutz, 1990] CHEESEMAN, P.; STUTZ, J.: "Bayesian classification (autoclass): Theory and results advances in knowledge discovery and data mining". http://ic.arc.nasa.gov/ic/projects/bayes-group/autoclass-c-program.html.

[Cho et al., 1998] CHO, J.; GARCIA-MOLINA, H. \& PAGE L. (1998): "Efficient crawling through URL ordering" Proc. 7th Intern. WWW Conference, Brisbane, Australia. Abril.

[Conklin, 1987] CONKLIN, J. (1987): "Hypertext: An Introduction and Survey". IEEE Computer, v.20, n.9, p.17-41, Setembro.

[Craven \& Slattery, 2001] CRAVEN, M.; SLATTERY, S. (2001): "Relational Learning with Statistical Predicate Invention: Better Models for Hypertext". Machine Learning, n.43, v.1-2, p.97-119.

[Craven et al., 2000] CRAVEN, M.; DIPASQUO, D.; FREITAG, D.; MCCALLUM, A.; MITCHELL, T.; NIGAM, K. \& SLATTERY, S. (2000): "Learning to Construct Knowledge Bases from the World Wide Web". Artificial Intelligence, n.118, v.1-2, p.69-113. 
[De Bra, 2000] DE BRA, P. M. E. (2000): "Using hypertext metrics to measure research output levels". Scientometrics, v.47, n.2, p.227-236, Kluwer Academic Publishers.

[De Bra, 1999] DE BRA, P. M. E. (1999): "Hypermedia Structure and Systems". Eidhoven University of Technology, http://wwwis.win.tue.n1/2L670/static/.

[Decker \& Focardi, 1995] DECKER, K. M.; FOCARDI, S.: "Technology overview: A report on data mining". Technical report, CSCS-ETH, Swiss Scientific Computing Center.

[Fenton \& Pfleeger, 1998] FENTON, N; PLFLEEGER, S.: Software Metrics: A Rigorous \& Practical Approach, 2nd Edition, PWS Publishing Co., 1998.

[Fortes \& Nicoletti, 1999] FORTES, R. P. M.; NICOLETTI, M. C. (1999): "Automatic Diagnosis of Hyperdocuments Using a Family of Quantifiable Metrics" In: SoST'99 (Symposium on Software Technology) Proceedings, Buenos Aires, Argentina, p.62-71, Setembro.

[Fortes \& Nicoletti, 1997a] FORTES, R. P. M.; NICOLETTI, M. C. (1997): "A Family of Link Based Metrics for the Evaluation of Web Documents" SIGLINK Bulletin, v.6, n.3, p.21-23, Outubro.

[Fortes \& Nicoletti, 1997b] FORTES, R. P. M.; NICOLETTI, M. C. (1997): "LiOS: a tool for supporting evaluation in the WWW" Hypertextes et Hypermédias, v.1, n. 2-4, p.77-85, 1997, Actes de la 4e Conférence Internationale Hypertextes et Hypermédias, Paris.

[Fortes, 1996] FORTES, R. P. M.: "Análise e Avaliação de Hiperdocumentos: uma abordagem baseada na Representação Estrutural". Tese de Doutorado, IFSCUSP, São Carlos - SP. 30 de agosto de 1996. 179p.

[Garzotto et al., 1995] GARZOTTO, F.; MAINETTI, L. \& PAOLINI, P. (1995): "Hypermedia Design, Analysis, and Evaluation Issues", Communications of the ACM, Special Issue on Hypermedia Design, Agosto.

[Garzotto \& Paolini, 1999] GARZOTTO, F.; PAOLINI, P.: "Design and Evaluation of Cultural Multimedia". http://www.archimuse.com/ichim99/abstracts/prg_1047.html.

[Halasz, 1988] HALASZ, F. G. (1988): "Reflections on Notecards: Seven issues for the Next Generation of Hypermedia System". Communications of the ACM, v.31, n.7, p.836-852, Julho.

[Halstead, 1977] HALSTEAD, M. H.: "Elements of Software Science". New York, Elsevier North Holland, 1977. 
[Hatzimanikatis et al., 1995] HATZIMANIKATIS, A. E.; TSALIDIS, C. T. \& CHRISTODOULAKIS, D. (1995): "Measuring the Readability and Maintainability of Hyperdocuments"; J. of Software Maintenance, Research and Practice, v.7, p.77-90.

[Henzinger, 2001] HENZINGER, M. R. (2001): "Hyperlink Analysis for the Web". In IEEE Internet Computing, p.45-50.

[HTML, 1999] Tutorial HTML do ICMC, http://www.icmc.sc.usp.br/manuals/HTML/.

[ISO/IEC 9126] "Information Technology - Software Product Evaluation - Quality characteristics and guidelines for their use", Junho 1991.

[Kan, 1995] KAN, S.H. Metrics and Models in Software Quality Engineering. USA, AddisonWesley, 1995.

[Koster, 1995] KOSTER, M.: "Robots in the Web: threat or treat?", ConneXions, v.9, n.4, Abril 1995.

[Lohse \& Spiller, 1998] LOHSE, G.; SPILLER, P.: "Electronic Shopping", CACM 41,7 (Julho1998); p.81-86.

[Martins et al., 2001] MARTINS, C. A.; MONARD, M. C.; HAEDO, A. S. \& MATSUDO, N. L.: "Uma metodologia para auxiliar o processo de interpretação semi-automática de clusters" Relatório Técnico do ICMC, n.133, Março de 2001.

[Martins \& Monard, 2000] MARTINS, C. A.; MONARD, M. C. (2000): "Interpretação de Clusters Utilizando Aprendizado de Máquina Simbólico"; 21 Iberian Latin American Congress on Computational Methods in Engineering - CILAMCE2000, Rio de Janeiro (RJ).

[McCall et al., 1977] MCCALL, J. A; RICHARDS, P. K. \& WALTERS, G. F. (1977): "Factors in Software Quality“, RADC TR-77-369.

[McCallum et al., 2000] MCCALLUM, A.; NIGAM, K. \& UNGAR, L.: "Efficient clustering of high-dimensional data sets with application to reference matching". $K D D(2000)$.

[Mendes et al., 2001] MENDES, E.; COUNSELL, S.; MOSLEY, N. (2001): "Measurement and Effort Prediction for Web Applications". Web Engineering 2001, p.295-310.

[Nanard \& Nanard, 1995] NANARD, J.; NANARD, M. (1995): "Hypertext Design Environments and the Hipertext Design Process". Communications of the Association of Computer Machinery, v.38, n.8, p.49-56.

[Nielsen, 2001] NIELSEN, J.: The Alertbox, http://www.useit.com/alertbox/ 
[Nielsen, 1996] NIELSEN, J.: "Why frames suck most of the time", http://www.useit.com/alertbox/9612.html

[Nielsen, 1999] NIELSEN, J.: "Top Ten Mistakes" Revisited Three Years Later", http://www.useit.com/alertbox/990502.html

[OIsina et al., 1999] OLSINA, L.; LAFUENTE, G.; ROSSI, G. (1999): "Specifying Quality Characteristics and Attributes for Websites", Proc. First ICSE Workshop on Web Engineering, ACM, Los Angeles, Maio.

[Papast, 1997] PAPAST, P.: Hypermedia Navigation Metrics, http://ise.eng.uts.edu.au/ise/hyptech/miniprj/mnprj97a/papast/metrics.html (1997).

[Pazzani \& Billsus, 1997] PAZZANI, M.; BILLSUS, D. (1997): "Learning and Revising User Profiles: The identification of interesting web sites". Machine Learning, v.27, p..313-331.

[Pinkerton, 1994] PINKERTON, B. (1994): "Finding what people want: experiences with the WebCrawler", in: Proc. of the 2nd International WWW Conference, Chicago, USA, Outubro, p.17-20.

[Pressman, 2000] PRESSMAN, R. S.: "Software Engineering: A Practitioner's Approach", McGraw-Hill , $5^{a}$ edição, 2000.

[Quinlan, 1993] QUINLAN, J. R.: “C4.5: Programs for Machine Learning”. MK, Los Altos, California, USA.

[Russel \& Norvig, 1995] RUSSEL, S. J.; NORVIG, P.: Artificial Intelligence: $A$ Modern Approach. Prentice Hall, 1995.

[Sanches et al., 2000] SANCHES, R.; FABBRI, S. C. P. F. \& MALDONADO, J. C.: "Qualidade de Software: da engenharia de software aos modelos de qualidade", Anais VI Escola Regional de Informática de São Paulo da SBC, São Carlos - SP, Abril, p.219-240.

[Seraphim \& Fortes, 2000] SERAPHIM, E.; FORTES, R. P. M (2000): "DB-LiOS: Suporte Automático à Avaliação da Consistência de Links em WWW" - In: XX Congresso Nacional da SBC, XXVII SEMISH, Anais. Curitiba-PR, Julho.

[Silva et al., 1999] SILVA, A. S.; VELOSO, E. A.; GOLGHER P. B.; RIBEIRO-NETO B.; ZIVIANI, N.; LAENDER, A. H. F. (1999): "CobWeb - Um Coletor Automático de Documentos Web" Anais do XIX Congresso Nacional da Sociedade Brasileira de Computação, XXVI SEMISH, v.1, p.233-247, Julho. 
[Silva \& Fortes, 2001] SILVA, E. A.; FORTES, R. P. M.: "Web Structure Metrics: an analysis using Machine Learning systems" - artigo aceito a ser apresentado no ASSE'2001 (Second Argentine Symposium on Software Engineering) parte da 30th Argentine Conference on Computer Science and Operational Research (JAllO 2001) http://www.ing.unlpam.edu.ar/jaiio2001/.

[Stotts et al., 1992] STOTTS, P. D.; FURUTA, R. \& RUIZ, J. C. (1992): "Hyperdocuments as Automata: Trace-Based Browsing Property Verification". In: European Conference on Hypertext, New York, p.272-281.

[Szwarcfiter, 1984] SZWARCFITER, J. L.: Grafos e algoritmos computacionais. Rio de Janeiro, Campus, 1984.

[Thistlewaite, 1995] THISTLEWAITE, P. (1995): "Automatic Construction of Open Webs using Derived Link Patterns". In M. Agosti and J. Allan (Eds.), IR and Automatic Construction of Hypermedia: a Research Workshop. ACM SIGIR.

[Thüring et al., 1995] THÜRING, M.; HANNEMANN, J.; HAAKE, J. M. (1995): “Hypermedia and Cognition: Designing for Comprehension". Communications of the ACM, v.38, n.8, p.57-66.

[Wall et al., 1996] WALL, L.; CHRISTIANSEN, T. \& SCHWARTZ, R. L.: Programming in PERL. O'Reilly, Inc., 1996. 